\title{
Amyloid $\beta$ Induces the Morphological Neurodegenerative Triad of Spine Loss, Dendritic Simplification, and Neuritic Dystrophies through Calcineurin Activation
}

\author{
Hai-Yan Wu, ${ }^{1}$ Eloise Hudry, ${ }^{1}$ Tadafumi Hashimoto, ${ }^{1}$ Kishore Kuchibhotla, ${ }^{1,2}$ Anete Rozkalne, ${ }^{1}$ Zhanyun Fan, ${ }^{1}$ \\ Tara Spires-Jones, ${ }^{1}$ Hong Xie, ${ }^{1}$ Michal Arbel-Ornath, ${ }^{1}$ Cynthia L. Grosskreutz, ${ }^{3}$ Brian J. Bacskai, ${ }^{1}$ \\ and Bradley T. Hyman ${ }^{1}$ \\ ${ }^{1}$ Department of Neurology/Alzheimer's Disease Research Laboratory, Massachusetts General Hospital, Charlestown, Massachusetts 02129, ${ }^{2}$ Program in \\ Biophysics, Harvard University, Cambridge, Massachusetts 02138, and ${ }^{3}$ Department of Ophthalmology, Massachusetts Eye and Ear Infirmary, Boston, \\ Massachusetts 02114
}

Amyloid $\beta(\mathrm{A} \beta)$-containing plaques are surrounded by dystrophic neurites in the Alzheimer's disease (AD) brain, but whether and how plaques induce these neuritic abnormalities remain unknown. We tested the hypothesis that soluble oligomeric assemblies of $\mathrm{A} \beta$, which surround plaques, induce calcium-mediated secondary cascades that lead to dystrophic changes in local neurites. We show that soluble $\mathrm{A} \beta$ oligomers lead to activation of the calcium-dependent phosphatase calcineurin (CaN) (PP2B), which in turn activates the transcriptional factor nuclear factor of activated T cells (NFAT). Activation of these signaling pathways, even in the absence of $A \beta$, is sufficient to produce a virtual phenocopy of $A \beta$-induced dystrophic neurites, dendritic simplification, and dendritic spine loss in both neurons in culture and in the adult mouse brain. Importantly, the morphological deficits in the vicinity of $A \beta$ deposits in a mouse model of AD are ameliorated by $\mathrm{CaN}$ inhibition, supporting the hypothesis that $\mathrm{CaN}-\mathrm{NFAT}$ are aberrantly activated by A $\beta$ and that CaN-NFAT activation is responsible for disruption of neuronal structure near plaques. In accord with this, we also detect increased levels of an active form of $\mathrm{CaN}$ and NFATc 4 in the nuclear fraction from the cortex of patients with AD. Thus, $A \beta$ appears to mediate the neurodegeneration of AD, at least in part, by activation of $\mathrm{CaN}$ and subsequent NFAT-mediated downstream cascades.

\section{Introduction}

Amyloid $\beta(\mathrm{A} \beta)$ peptide, the major component of senile plaques, accumulates in the brain of Alzheimer's disease (AD) patients (Walsh and Selkoe, 2004; Yaari and Corey-Bloom, 2007). The amyloid hypothesis (Hardy and Allsop, 1991; Hardy and Selkoe, 2002) suggests that $A \beta$ induces neurodegeneration, but the key molecular mechanisms that link $\mathrm{A} \beta$ to neuronal damage remain a critical gap in understanding $\mathrm{AD}$ and designing effective therapeutics. Exposure of neurons to synthetic or naturally secreted $\mathrm{A} \beta$ peptides induces a reduction of dendritic spines and synaptic dysfunction in culture and causes memory deficits in learned behavior in normal rats (Pike et al., 1993; Lorenzo and Yankner, 1994; Geula et al., 1998; Shankar et al., 2007, 2008). In vivo studies using longitudinal multiphoton microscopy reveal a direct toxic effect on neurites surrounding $A \beta$ deposits, including dendritic simplification, loss of dendritic spines, and neuritic dystrophies (Spires et al., 2005; Meyer-Luehmann et al., 2008). However, the

Received Sept. 9, 2009; revised Dec. 29, 2009; accepted Jan. 5, 2010.

This work was supported by National Institutes of Health Grants AG08487, EB000768, and EY13399 and a French Foundation award. We thank Dr. Jeffery D. Molkentin (Cincinnati Children's Hospital) for providing the following constructs: CaN, CaN inhibitory peptide (hAKAP79), and NFAT luciferase reporter. We thank Daniel Joyner for primary neuron preparation, and Meihua Deng, Kelly Han, and Luxiang Cao for technical assistance.

Correspondence should be addressed to Dr. Bradley T. Hyman, Massachusetts General Institute for Neurodegenerative Disease, 114 16th Street, Charlestown, MA 02129. E-mail: bhyman@partners.org.

DOI:10.1523/JNEUROSCI.4456-09.2010

Copyright $\odot 2010$ the authors $\quad 0270-6474 / 10 / 302636-14 \$ 15.00 / 0$ connection between extracellular $\mathrm{A} \beta$ and the intracellular signaling pathways that cause local disruption of neuronal processes, synaptic dysfunction, and neurodegeneration are unknown.

Elevated intracellular calcium has been observed in neurons exposed to $A \beta$ in several model systems, and disrupted calcium homeostasis has been suggested to play a central role in $\mathrm{AD}$ pathogenesis (Palotás et al., 2002; Mattson, 2004; Smith et al., 2005; Stutzmann, 2005; Bezprozvanny and Mattson, 2008; Busche et al., 2008). For example, we have recently demonstrated that neurites in amyloid precursor protein (APP)-overexpressing transgenic ( $\mathrm{Tg}$ ) mice have significantly elevated intracellular calcium $\left(\left[\mathrm{Ca}^{2+}\right]_{\mathrm{i}}\right)$ compared with age-matched nontransgenic controls (Kuchibhotla et al., 2008).

In neurons, $\mathrm{Ca}^{2+}$ signaling is tightly controlled to ensure proper functioning of numerous $\mathrm{Ca}^{2+}$-dependent events, including processes influenced by the serine/threonine phosphatase calcineurin (CaN) (Mulkey et al., 1994; Wang and Kelly, 1996; Halpain et al., 1998; Berridge et al., 2000). CaN is the only $\mathrm{Ca}^{2+}$-activated protein phosphatase in neurons, and it is involved in many facets of neuronal physiology, including synaptic plasticity, and learning and memory (Klee et al., 1979; Winder and Sweatt, 2001). In mice, both genetic and pharmacological upregulation of the expression of CaN can induce synaptic dysfunction and memory impairment, whereas CaN inhibition strengthens memory in spatial learning tasks (Malleret et al., 2001; Winder and Sweatt, 2001; Mansuy, 2003). We explored the 
possibility that $\mathrm{AD}$-related neuritic degeneration may involve altered CaN activity as a result of $\mathrm{Ca}^{2+}$ dyshomeostasis.

In the present study, we establish an in vitro model of $\mathrm{A} \beta$ induced neuritic damage. Using this model, we established molecular links between exposure to extracellular $A \beta$ and the morphological changes that occur in neurites around plaques. We find that soluble $\mathrm{A} \beta$ from $\mathrm{Tg} 2576$ conditioned medium $(\mathrm{CM})$ induces $\mathrm{CaN}$ activation and subsequent nuclear factor of activated T cells (NFATc4) nuclear translocation, which leads to dendritic spine loss, dendritic simplification, and neuritic dystrophies. Blocking A $\beta$, CaN activation, or, importantly, NFAT activation is each sufficient to prevent $A \beta$-induced morphological alterations. Moreover, plaque-associated neurodegenerative changes in an APP-overexpressing mouse model of AD can be blocked by inhibiting CaN. These data suggest that CaN activation and subsequent activation of NFAT-mediated transcriptional cascades are critically involved in $\mathrm{A} \beta$-induced neurotoxicity, providing mechanistic insight into the "black box" between $A \beta$ and synaptic failure.

\section{Materials and Methods}

Primary neuronal cultures. The animals used for generating cell cultures were transgenic mice expressing human APP (Tg2576 line: transgenic mice overexpressing the 695 aa isoform of human Alzheimer $\beta$-amyloid precursor protein containing the double Swedish mutation K670N, M671L with a hamster prion protein gene promoter in B6;SJL F2 mice (Hsiao et al., 1996). Primary neuronal cultures were derived from cerebral cortex of embryonic days 15-19 Tg2576 mice (Charles River Laboratories), as described previously (Wu et al., 2004) with modifications. Briefly, cortices were dissected, gently minced, trypsinized $(0.027 \%$, $37^{\circ} \mathrm{C} ; 5 \% \mathrm{CO}_{2}$ for $15 \mathrm{~min}$ ), and then washed with $1 \times$ HBSS. Neurons were seeded to a density of $4 \times 10^{5}$ viable cells $/ 35 \mathrm{~mm}$ culture dishes previously coated with poly-D-lysine $(100 \mu \mathrm{g} / \mathrm{ml})$ for at least $1 \mathrm{~h}$ at $37^{\circ} \mathrm{C}$. Cultures were maintained at $37^{\circ} \mathrm{C}$ with $5 \% \mathrm{CO}_{2}$, supplemented with Neurobasal medium with 2\% B27 nutrient, 2 mM L-glutamine, penicillin (100 U/ml), and streptomycin $(100 \mu \mathrm{g} / \mathrm{ml})$. The cultures were used within $28 d$ in vitro (DIV). To maintain elevated levels of extracellular $\mathrm{A} \beta$, media were not changed. To identify the genotype of the animals, we used PCR on DNA extracted from sample tail taken after dissection of the cerebral cortex.

Adeno-associated viral construction. Adeno-associated viral (AAV) with an expression cassette of the chicken $\beta$-actin promoter driving enhanced green fluorescent protein (GFP), the mouse CaN isoform cDNA corresponding to wild type (CaNwt), the posttranslationally truncated form of CaNA encoding $45 \mathrm{kDa}$ isoform (CaNCA), or AKAP79 peptide, flanked by the AAV inverted terminal repeats, was described previously (Spires et al., 2005). CaNwt, CaNCA (amino acid residues 1-399), and a peptide corresponding to human AKAP79 (hAKAP79) (amino acid residues 60-358) were subcloned into AAV-cytomegalovirus (CMV)/ chicken $\beta$-actin (CBA)-woodchuck posttranscriptional regulatory element (WPRE) vector. Each construct was amplified by the following primers: (1) hemagglutinin (HA)-CaNwt-V5, 5' -GAATTCATGTATCCGTATGACGTACCAGAGTACGCCATGTCCGAGCCCAAGGCGATTGATCC; (2) HA-CaNwt-V5, 3'-GCTAGCTCACGTACTGTCGAGTCCCAGGAGAGGGTTTGGGATCGGCTTGCCCTGGATATTGCTGCTATTACTGCCATTGC; (3) HA-CaNCA, 3'-CTAGTTCTGATGACTTCCTTCCGGGCTGCGGCCGTC; (4) Flag-hAKAP79, 5'-GAAGTTATCAGTCGACATGGACTACAAAGACGATGACGACAAGGGCAGGAAGTGTCCACAA; and (5) Flag-hAKAP79, 3'-ATGGTCTAGAAAGCTTCTAGACATTTTTAGATTTTGTAACATCAAATTCACTGATTTC. All the constructs were verified by sequencing.

Immunocytochemistry. Immunocytochemistry was performed as described previously (Wu et al., 2004). Briefly, after being treated under different experimental conditions, cells were fixed with $4 \%$ paraformaldehyde in PBS, pH 7.4, for 15 min and were then membrane permeabilized with $0.5 \%$ Triton X-100 in PBS for 5 min. After blocking with 3\% bovine serum albumin at $37^{\circ} \mathrm{C}$ for $1 \mathrm{~h}$, cells were incubated with primary antibodies: anti-microtubule-associated protein 2 (MAP2) antibody (1: 200; Sigma), or anti-NFATc4 antibody (1:200; Santa Cruz Biotechnology), anti-HA antibody (1:200; Invitrogen), or anti-Flag antibody (1:200; Sigma), at $4^{\circ} \mathrm{C}$ overnight. Cells were then incubated with secondary antibodies conjugated to either cyanine 3 (Cy3) (1:500; Jackson ImmunoResearch) or Alexa 488 (1:500; Invitrogen). Fluorescent images were obtained using an LSM 510 Carl Zeiss microscope with a $25 \times$ or a $63 \times$ water-immersion objective lens. All images were taken at $512 \times 512$ pixel resolution. Nuclear NFATc4 staining was determined by overlap of NFATc4 staining with Hoechst nuclear staining. To calculate the NFATc4 ratio of nucleus versus cytoplasm, the intensity of nuclear NFATc4 was divided by the intensity of cytoplasmic NFATc4.

Immunohistochemistry. Immunohistochemistry was performed as described previously (Spires et al., 2005). Briefly, animals were killed with an overdose of ketamine $(30 \mathrm{mg} / \mathrm{kg})$ and xylazine $(3 \mathrm{mg} / \mathrm{kg})$, and the brain was fixed in $4 \%$ paraformaldehyde in phosphate buffer with $15 \%$ glycerol cryoprotectant. Sections of $100 \mu \mathrm{m}$ were cut on a freezing microtome, washed extensively in $0.1 \mathrm{~m}$ phosphate buffer, and processed as free-floating slices. Permeabilization and blocking was achieved by incubation of the sections for $1 \mathrm{~h}$ at room temperature in $0.1 \mathrm{M}$ phosphate buffer, $0.5 \%$ Triton X-100 (v/v), and 3\% bovine serum albumin. Primary antibodies for GFP (1:1000; Biogenesis), HA (1:100; Invitrogen), Flag (1:100; Sigma), and SMI312 (1:200; Sternberger Monoclonals) were applied overnight at $4^{\circ} \mathrm{C}$ in $0.1 \mathrm{~m}$ phosphate buffer with $3 \%$ bovine serum albumin. After extensive washing, appropriate secondary antibodies conjugated to Cy3 (1:100 dilution), Alexa 488 (1:100 dilution), or Cy5 (1:100 dilution) were applied for $1 \mathrm{~h}$ at room temperature. Micrographs of immunostaining were obtained using a $20 \times$ objective with an upright Olympus Optical BX51 fluorescence microscope with an Olympus Optical DP70 camera or using a $63 \times$ water-immersion objective with a Carl Zeiss confocal microscope.

Preparation of subcellular fractionation. Frozen tissue samples of human brain cortex $(250 \mathrm{mg})$ were homogenized in $0.32 \mathrm{M}$ sucrose lysis buffer [0.32 M sucrose, $5 \mathrm{~mm} \mathrm{CaCl}_{2}, 3 \mathrm{~mm} \mathrm{Mg}$ (acetate) $)_{2}, 0.1 \mathrm{~mm}$ EDTA, $10 \mathrm{~mm}$ Tris- $\mathrm{HCl}, \mathrm{pH} 8.0$, and $0.1 \%$ Triton X-100], supplemented with complete protease inhibitor cocktail tablets and centrifuged at $800-$ $g$ for $15 \mathrm{~min}$ at $4^{\circ} \mathrm{C}$. The supernatants were centrifuged at $100,000 \times g$ for $1 \mathrm{~h}$ at $4^{\circ} \mathrm{C}$, and the resulting supernatants were regarded as the cytosolic fractions. The pellets from the initial centrifugation step were resuspended in $1.8 \mathrm{~m}$ sucrose buffer containing $1.8 \mathrm{M}$ sucrose, 3 $\mathrm{mm} \mathrm{Mg}$ (acetate) $)_{2}, 1 \mathrm{~mm}$ DTT, and $10 \mathrm{~mm}$ Tris- $\mathrm{HCl}, \mathrm{pH}$ 8.0, supplemented with complete protease inhibitor cocktail tablets (Roche Diagnostics). The nuclei were pelleted by centrifugation at $12,400 \times g$ for $1 \mathrm{~h}$ at $4^{\circ} \mathrm{C}$. The pellet was resuspended in $0.32 \mathrm{M}$ sucrose buffer and washed by low-speed centrifugation. The final pellet was designated as the nuclear fraction.

For Western blot analyses, equal amounts of protein $(20 \mu \mathrm{g})$ from each fraction were separated on a 4-20\% SDS-PAGE gel. Primary antibodies for CaN (Stressgen) and NFATc4 (Santa Cruz Biotechnology) were used. Primary antibody incubation was followed by rabbit polyclonal horseradish peroxidase linked secondary antibody (1:1000; Bio-Rad). Immunoreactivity was visualized using enhanced chemiluminescence reagent (PerkinElmer Life and Analytical Sciences) and exposure on x-ray film. Anti-glyceraldehyde-3-phosphate dehydrogenase (GAPDH) antibody (Millipore Corporation) and anti-histone deacetylase 1 (HDAC1) antibody (Affinity BioReagents) were used to verify the integrity of the cytoplasmic and nuclear fraction separation.

Separation of $A \beta$ oligomers by size exclusion chromatography. Five milliliters of cultured media from 14 DIV wild-type or Tg neuron cultures was collected and centrifuged at $3000 \times g$ at $4^{\circ} \mathrm{C}$ in Amicon Ultra-15ML $3 \mathrm{~K}$ (Millipore Corporation) to concentrate proteins approximately fivefold. Concentrated cultured media $(750 \mu \mathrm{l})$ was separated by size exclusion chromatography (SEC) on Superdex 75 10/300 GL column (GE Healthcare) in $50 \mathrm{~mm}$ ammonium acetate, $\mathrm{pH} 8.5$, with AKTA purifier 10 (GE Healthcare) (Townsend et al., 2006).

ToxiLight BioAssay. Cell viability was determined in wild-type or $\mathrm{Tg}$ neurons at both 7 and 14 DIV using the ToxiLight BioAssay kit from Lonza. Preparation of cell extracts and the cytotoxicity assay were performed according to the protocol of the manufacturer. 
$A \beta$ assay. $A \beta$ levels were assayed from the medium collected from culture dishes at a different date, using an ELISA. A $\beta$ concentration was determined with a sandwich ELISA kit (Wako) and with BAN50/BA27 for $\mathrm{A} \beta_{40}$ and $\mathrm{BAN} 50 / \mathrm{BC} 05$ for $\mathrm{A} \beta_{42}$ in cultured medium and with BNT77/BA27 for $\mathrm{A} \beta_{40}$ and BNT77/BC05 for $\mathrm{A} \beta_{42}$ in fractionated samples by size-exclusion chromatography. Samples was optimized to detect $\mathrm{A} \beta$ in the range of $6.25-100 \mathrm{fmol} / \mathrm{ml}$. ELISA signals were reported as the mean \pm SD of two replica wells in femtomoles of $A \beta$ per milligram of protein (determined with the BCA Protein Assay Reagent kit; Pierce).

Immunoprecipitation $A \beta$ from cultured medium. Cultured medium of wild-type or Tg cultures at 14 DIV were collected. Medium was centrifuged at $1200 \mathrm{rpm}$ for $5 \mathrm{~min}$ at $4^{\circ} \mathrm{C}$ to remove cellular debris. Supernatants $(1.3 \mathrm{ml})$ for each condition were precleared with $50 \mu$ l of protein $\mathrm{G}$ Sepharose (Sigma) for $1 \mathrm{~h}$ at $4^{\circ} \mathrm{C}$ with gentle shaking and then centrifuged at $15,000 \mathrm{rpm}$ at $4^{\circ} \mathrm{C}$ for $5 \mathrm{~min}$. Supernatants were incubated with $5 \mu \mathrm{g}$ of anti-6E10 antibody or $5 \mu \mathrm{g}$ of anti-GFP (Abcam) as control. After an overnight incubation at $4^{\circ} \mathrm{C}$, protein $\mathrm{G}$ Sepharose $(60 \mu \mathrm{l})$ was added and incubated at $4^{\circ} \mathrm{C}$ for $2 \mathrm{~h}$. Beads were isolated by centrifugation $\left(15,000 \mathrm{rpm}, 4^{\circ} \mathrm{C}\right.$ for $\left.5 \mathrm{~min}\right)$ and subsequently washed three times with TBS buffer before the addition of $2 \times$ Laemli's sample buffer.

$\left[\mathrm{Ca}^{2+}\right]_{i}$ measurements. Primary neurons were plated on $35 \mathrm{~mm}$ glassbottomed dishes (MatTek) and maintained in a standard Neurobasal medium without Phenol Red. Calcium levels were evaluated in wild-type neurons treated for $24 \mathrm{~h}$ with wild-type or Tg conditioned media as well as with transgenic conditioned media that was pre-depleted with 3D6 antibody. In all cases, calcium imaging was performed using Indo-1 as described previously (Bacskai et al., 2003). Briefly, Indo-1/AM (Invitrogen) was dissolved with 20\% pluronic F-127 (Invitrogen) in DMSO and then added to the culture dishes at a final concentration of $1 \mu \mathrm{M}$ Indo$1 / \mathrm{AM}$ and $0.02 \%$ pluronic F-127 for $45 \mathrm{~min}$. Cells were imaged with an Olympus Optical Fluoview 1000MPE with pre-chirp optics and a fast acousto-optical modulator mounted on an Olympus BX61WI upright microscope and an Olympus Optical 20× dipping objective (numerical aperture, 0.95). A mode-locked titanium/sapphire laser (MaiTai; Spectra Physics) generated two-photon fluorescence with $750 \mathrm{~nm}$ excitation, and the emitted light was discriminated into two channels with interference filters corresponding to $390 \mathrm{~nm}, 65 \mathrm{~nm}$ bandpass and $495 \mathrm{~nm}, 20 \mathrm{~nm}$ bandpass (Chroma Technology) for ratiometric imaging. The capture settings remained unchanged for the entire experiment. Fluorescence emission ratios were calculated in the neuronal cell bodies. To convert the calculated ratios into calcium concentrations, primary neurons were incubated with Indo$1 / \mathrm{AM}$ and treated with either calcium-free or $39 \mu \mathrm{M}$ calcium buffers in the presence of $20 \mu \mathrm{M}$ ionomycin for $15 \mathrm{~min}$. The calcium-free and calciumsaturated ratios were then measured and used as the $R_{\min }$ and $R_{\max }$. These ratios along with the $K_{\mathrm{D}}$ of Indo- 1 for calcium of $250 \mathrm{~nm}$ (Grynkiewicz et al., 1985 ) were used for calculation of calcium concentration.

Luciferase reporter assay. CaNwt, CaNCA, or NFAT-TA-Luc (Clontech) was subcloned into AAV serotype 2 vector. These plasmids $(1 \mu \mathrm{g})$ were used as primary neurons at 3 DIV. After $24 \mathrm{~h}$, the cells were harvested and luciferase activities were measured with a luminometer using a reagent kit (Luciferase Assay System with Reporter Lysis Buffer; Promega). The background luciferase activity was subtracted from all experiments.

Experimental animals. C57BL/6J wild-type mice and double transgenic mice (B6C3APPswe/PS1dE9 line; The Jackson Laboratory) overexpressing mutant human APP and mutant human Presenilin 1 (PS1), as well as transgenic mice expressing human Swedish mutated APP (Tg2576 line) were used. These mice were housed in the animal facility, and C57BL/6J wild-type and APP/PS1 mice were used at the age of 5-6 months for intracortical injection. All experiments were performed in accordance with animal protocols approved by the Institutional Animal Care and Use Committee.

Intracortical injections and surgery. Intracortical injections and surgery were performed as described previously (Spires et al., 2005; Kuchibhotla et al., 2008; Meyer-Luehmann et al., 2008). Briefly, mice were anesthetized with ketamine $(10 \mathrm{mg} / \mathrm{kg})$ and xylazine $(1 \mathrm{mg} / \mathrm{kg})$ and placed in a stereotaxic apparatus. The surgical site was sterilized with betadyne and isopropyl alcohol, and a $2-3 \mathrm{~mm}$ incision was made in the scalp along the midline between the ears. Burr holes were drilled in the skull, $0.5 \mathrm{~mm}$ posterior from bregma, and $0.5 \mathrm{~mm}$ lateral to the midsagittal line. Using a Hamilton syringe, $3 \mu$ l of virus (titer, $4.2 \times 10^{12}$ viral genomes $/ \mathrm{ml}$ ) was injected $1.2 \mathrm{~mm}$ deep in somatosensory cortex at a rate of $0.25 \mu \mathrm{l} / \mathrm{min}$. After one injection in each burr hole, the scalp was sutured, and the mouse recovered from anesthesia on a heating pad.

Three to 4 weeks after injection, APP/PS1 transgenic mice received an intraperitoneal injection of methoxy- $\mathrm{XO}_{4}(10 \mathrm{mg} / \mathrm{kg})$, a fluorescent compound that crosses the blood-brain barrier and binds to amyloid plaques (Klunk et al., 2002). A cranial window of $6 \mathrm{~mm}$ in diameter was installed under anesthesia $(10 \mathrm{mg} / \mathrm{kg}$ ketamine and $1 \mathrm{mg} / \mathrm{kg}$ xylazine $)$. At the same time, Texas Red dextran (70,000 Da molecular weight; 12.5 $\mathrm{mg} / \mathrm{ml}$ in sterile PBS; Invitrogen) was injected into a lateral tail vein to provide a fluorescent angiogram.

Multiphoton imaging. Images of GFP-filled neuronal processes and, in the case of APP/PS1 mice, amyloid pathology, and blood vessels were obtained using a Bio-Rad 1024ES multiphoton microscope (Bio-Rad), mounted on an Olympus Optical BX50WI upright microscope. A wax ring was placed on the edges of the coverslip of the cortical window and filled with distilled water to create a well for an Olympus Optical $20 \times$ dipping objective (numerical aperture, 0.95). A mode-locked titanium/sapphire laser (MaiTai; Spectra Physics) generated two-photon fluorescence with $800 \mathrm{~nm}$ excitation, and detectors containing three photomultiplier tubes (Hamamatsu) collected emitted light in the range of 380-480, 500-540, and 560-650 nm (Bacskai et al., 2003). GFP-filled neuronal processes were sampled $\sim 100 \mu \mathrm{m}$ below the surface of the brain around somatosensory cortex. At the end of imaging sessions, mice were allowed to recover and placed singly in their home cage.

Labeling of fibrillar amyloid deposits. After immunohistochemistry, fibrillar amyloid deposits (neuritic plaques) were stained for $8 \mathrm{~min}$ in a solution of thioflavin $\mathrm{S}(2 \mu \mathrm{g} / \mathrm{ml})$ in $0.1 \mathrm{M}$ PBS and then rinsed with $\mathrm{ddH}_{2} \mathrm{O}$.

Statistical analyses. Data are presented as mean $\pm \mathrm{SD}$. We made comparisons between groups by one- or two-way ANOVA, followed by post hoc Bonferroni's test for comparison among means. Differences with a $p$ value of $<0.05$ were considered statistically significant.

\section{Results}

\section{Abnormal morphologies in neurons from Tg2576 cultures}

Neuritic abnormalities are seen surrounding plaques in human $\mathrm{AD}$ and in aged APP-overexpressing mouse models of $\mathrm{AD}$, but studying these lesions is difficult because they are distributed apparently randomly throughout the cortical mantle, occur only in aged animals, and the location of new lesions cannot be predicted. We sought to develop a tractable model for neuronal abnormalities associated with $\mathrm{AD}$. We first examined whether mature primary neurons from transgenic embryos expressing APP with the familial Swedish mutation (Tg2576 line) develop any of the morphological phenotypes associated with neurodegeneration in the intact (aged) transgenic brain and in human $\mathrm{AD}$, including dendritic spine loss, diminished dendritic complexity, and neuritic dystrophies. To assess neuronal morphology, we transfected cultured neurons with GFP to label individual neurons. During the course of 21 DIV, GFP-positive neurons from $\mathrm{Tg} 2576$ ( $\mathrm{Tg}$ ) cultures progressively develop a neurodegenerative phenotype when compared with neurons from wild-type mice. In wild-type neurons at 14 DIV, GFP fluorescence demonstrated intricately branched dendritic arbors studded with protrusions that included mature spines and few fillopodia (Fig. $1 A 1, A 3)$. However, in Tg neurons, the maturation is accompanied by an increase in the number of neurons with focal neuritic swellings (Fig. 1A2,A4). The difference is marked; for example, at 14 DIV (Fig. $1 B$ ), the number of neurons with beaded neurites in Tg cultures is sevenfold higher than those in wild-type cultures. In addition, the number of neurons with dystrophic neurites increased with time (Fig. $1 \mathrm{~B}$ ). In Tg cultures, GFP-positive neurons with dystrophies are found in $14 \%$ of neurons at 14 DIV and in $24 \%$ at 21 DIV. Because some subtle morphological changes other than dendritic dystrophies, such as decreased dendritic branches and spine density, are also observed in the early stages of 
A
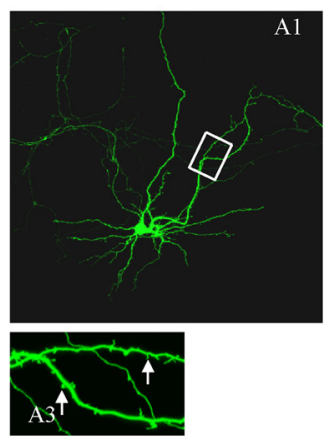

$\mathrm{C}$
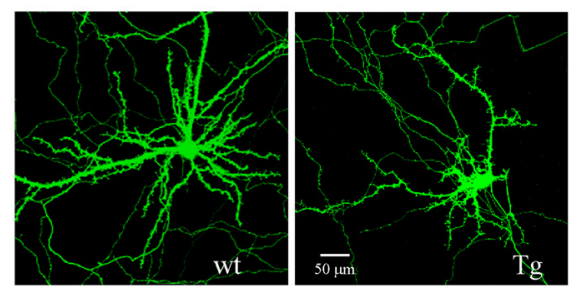

$\mathrm{D}$
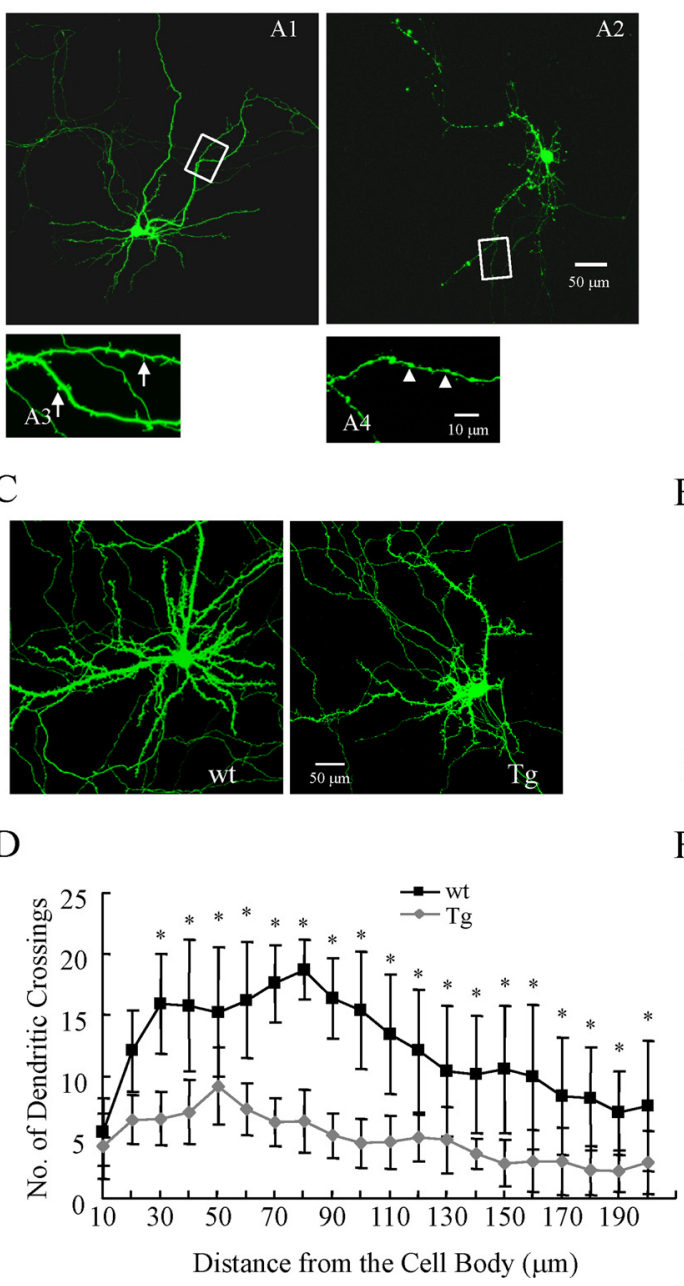

$\mathrm{B}$

E
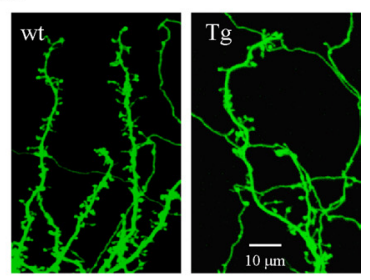

F

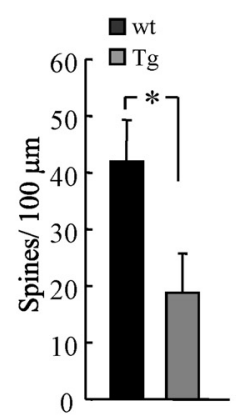

Figure 1. Abnormal morphologies in neurons from Tg cultures. $A$, Representative images of a wild-type GFP-labeled neuron at 14 DIV shows intricately branched dendritic arbors $(\boldsymbol{A 1}, \boldsymbol{A 3})$, whereas Tg neurons exhibit simplified dendritic complexity and localized dendritic dystrophies $(\boldsymbol{A 2}, \boldsymbol{A 4})$. $\boldsymbol{B}$, The percentage of neurons with dendritic dystrophies at 14 and 21 DIV was increased in Tg neurons compared with wild type (14 DIV: wild-type cultures, $2.0 \pm 0.2 \%$; Tg cultures, $14.0 \pm 2.0 \%, p<0.0001 ; 21$ DIV: wild-type cultures, $3.0 \pm 0.2 \%$; Tg cultures, $24.0 \pm 5.0 \% ; p<0.0001$, wild-type vs Tg; $p=0.0003,14$ vs 21 DIV). $n=50$ cells from each condition. C, Representative images of wild-type or Tg GFP-labeled mature neurons (21 DIV). D, Sholl analysis of total number of branch point on basal dendrites of neuron from wild-type and $\mathrm{Tg}$ cultures shows decreased complexity in $\mathrm{Tg}$ neurons starting at $30 \mu \mathrm{m}$ from the cell body. $n=25$ cells from each condition. $\boldsymbol{E}$, Representative GFP-labeled dendritic segments studded with mature spines from wild-type and $\mathrm{Tg}$ neurons show a loss of spines on $\mathrm{Tg}$ dendrites that is confirmed in quantitative assay of spine densities determined in neurons without apparent dystrophies at 21 DIV in wild-type and $\operatorname{Tg}$ cultures $(\boldsymbol{F}) . n=4$ culture per experiment and 400 spines from each condition. ${ }^{*} p<0.05$; ${ }^{* *} p<0.01$; data represent mean \pm SD.

neurodegeneration, we next compared dendritic branching and the density of dendritic spines of GFP-positive neurons from $\mathrm{Tg}$ and wild-type cultures. As measured by Sholl analysis, neurons in $\mathrm{Tg}$ cultures had reduced dendritic complexity at all points farther than $30 \mu \mathrm{m}$ from the cell body compared with wild-type cultures (Fig. 1C,D). These effects are not attributable solely to processes with overt morphological changes like dystrophies. For example, comparison of spine density in neurons (excluding neurons with dystrophies) between $\mathrm{Tg}$ and wild-type cultures showed that the mean spine density of $\mathrm{Tg}$ neurons is markedly lower than that of wild-type neurons (Fig. 1E,F). These effects are not attributable to overt toxicity; no typical apoptotic nuclei (chromatin condensation) appeared in Tg neurons compared with wild-type neurons (supplemental Fig. $1 \mathrm{~A}$, available at www.jneurosci.org as supplemental material). Toxilight assay for cell death showed no significant difference between wild-type and Tg neurons at either 7 or 14 DIV (supplemental Fig. 1B, available at www. jneurosci.org as supplemental material). Together, these results indicate that neurons with abnormal morphologies are limited in wild-type cultures, whereas in Tg cultures, neurons develop dystrophies, profound dendritic simplification, and loss of dendritic spines.

\section{Conditioned media from $\mathrm{Tg}$ culture contains oligomeric $\mathrm{A} \boldsymbol{\beta}$ and induces elevation of $\left[\mathrm{Ca}^{2+}\right]_{i}$}

Primary cortical neurons derived from $\mathrm{Tg}$ embryos at 14 DIV produced high levels of two major types of human $A \beta$ peptides, $\mathrm{A} \beta_{40}$ and $\mathrm{A} \beta_{42}$; the concentration of $\mathrm{A} \beta_{40}$ was $16 \mathrm{ng} / \mathrm{ml}$ and of $\mathrm{A} \beta_{42}$ was $1.2 \mathrm{ng} / \mathrm{ml}$ as determined by ELISA (supplemental Fig. $2 A, B$, available at www.jneurosci.org as supplemental material). Moreover, immunoprecipitation Western blot analysis revealed the presence of readily detectable SDS-stable small oligomers in CM of Tg cultures at 14 DIV, similar to those reported to be synaptotoxic (Shankar et al., 2008) (supplemental Fig. 2C, available at www. jneurosci.org as supplemental material).

We recently observed that neurites in the region near senile plaques contain high $\left[\mathrm{Ca}^{2+}\right]_{\mathrm{i}}$ (Kuchibhotla et al., 2008). To examine whether $A \beta$ is capable of inducing an increase in $\left[\mathrm{Ca}^{2+}\right]_{\mathrm{i}}$, we studied the effect of $\mathrm{Tg}$ neuronal culture $\mathrm{CM}$ on calcium homeostasis of wild-type neurons. Wild-type cortical neurons were cultured in standard $\mathrm{NB} / \mathrm{B} 27$ serum-free medium, and, at 14 DIV, the medium was replaced with diluted 1:2 CM from wild-type (wtCM) or $\mathrm{Tg}$ ( $\mathrm{TgCM})$ cultures and further incubated for 24 h. As shown in supplemental Figure $2 D$ (available at www.jneurosci.org as supplemental material), wild-type neurons treated with $\mathrm{TgCM}$ for $24 \mathrm{~h}$ exhibited elevated levels of $\left[\mathrm{Ca}^{2+}\right]_{\mathrm{i}}$ compared with neurons maintained in wild-type CM for $24 \mathrm{~h}$. There was no significant difference in $\left[\mathrm{Ca}^{2+}\right]_{\mathrm{i}}$ levels between untreated neurons and neurons treated with wtCM for $24 \mathrm{~h}$, indicating that the elevated levels of $\left[\mathrm{Ca}^{2+}\right]_{\mathrm{i}}$ specifically resulted from $\mathrm{TgCM}$. To determine whether $\mathrm{A} \beta$ caused the elevation of the $\left[\mathrm{Ca}^{2+}\right]_{i}$, we compared $\left[\mathrm{Ca}^{2+}\right]_{\mathrm{i}}$ between neurons applying $\mathrm{TgCM}$ with or without immunodepletion using 3D6 antibody, a high-titer monoclonal $\mathrm{A} \beta$ antibody (JohnsonWood et al., 1997). 3D6 immunodepletion completely prevented the elevation of $\left[\mathrm{Ca}^{2+}\right]_{\mathrm{i}}$ (supplemental Fig. $2 \mathrm{D}$, available at www. jneurosci.org as supplemental material).

CaN-NFATc4-aberrant nuclear localization in neurons from Tg cultures and human $\mathrm{AD}$ postmortem brain

Because $\mathrm{A} \beta$ in TgCM induces elevated $\left[\mathrm{Ca}^{2+}\right]_{\mathrm{i}}$ in cultured neurons and our previous study showing that neurites with abnormal morphologies in both APP/PS1 and APP transgenic mice were strongly associated with $\left[\mathrm{Ca}^{2+}\right]_{\mathrm{i}}$ overload (Kuchibhotla et al., 
2008), we examined $\mathrm{Ca}^{2+}$-mediated pathways as the link between exposure to $\mathrm{A} \beta$ and a neurodegenerative phenotype. Because $\mathrm{CaN}$ is the most calcium-sensitive protein phosphatase in the brain (Klee et al., 1979), we examined whether $\mathrm{CaN}$ activity is upregulated in neurons from $\mathrm{Tg}$ cultures. NFATc4, the nuclear factor of activated T cells, is a well known CaN substrate. Activation of the predominant neuronal NFATc4 isoform, which is abundantly expressed in cortical neurons, can be determined by its nuclear translocation after CaN-mediated dephosphorylation. Cultured neurons were stained with an antibody against endogenous NFATc4, a Hoechst counterstain for identification of nuclei, and MAP2, a neuron marker (Fig. 2A). The NFATc4 immunofluorescence intensity was measured, and the ratio of the intensity (nucleus vs cytoplasm) was compared in neurons from wild-type and Tg cultures. Very little colocalization of Hoechst nuclear staining and NFATc4 was found in wild-type neuron cultures, indicating that inactive NFATc4 is mostly located in the cytoplasm, whereas in Tg culture, NFATc4 staining was enhanced in nuclei (Fig. 2A,B). Similarly, CaN is known to translocate to the nucleus when activated, and Tg neuron cultures showed higher immunofluorescence intensity of CaN in the nucleus compared with wild-type neurons (Fig. 2C,D). These data show that $\mathrm{CaN}$ and NFAT are activated in Tg neurons.

To determine whether the aberrant nuclear localization of CaN-NFATc4 observed in Tg neurons could be relevant to the AD human condition, total homogenates, cytosol, and nuclei were prepared from frozen human $\mathrm{AD}$ or control cortex tissue samples and analyzed by immunoblotting with antibodies against endogenous NFATc4 or CaN (supplemental Table 1, available at www.jneurosci.org as supplemental material) (Fig. 2). NFATc4 immunoreactivity in the nuclear fraction prepared from AD samples was markedly increased compared with that seen in control samples, but no changes were observed in either the total homogenate or cytoplasmic fractions (Fig. 2E-G). Immunoblot analysis with $\mathrm{CaN}$ showed similar intensity of full-length $\mathrm{CaN}$ in all three compartments between $\mathrm{AD}$ and control (Fig. $2 H$ ). In contrast, we observed a consistent 2.2-fold increase in the level of a 45 $\mathrm{kDa}$ fragment of $\mathrm{CaN}$, a posttranslationally truncated form of CaN (CaNCA), which is constitutively active, in the nuclear fraction in $\mathrm{AD}$ samples compared with control samples (Fig. 2I). This proteolytic product removes the autoinhibi-
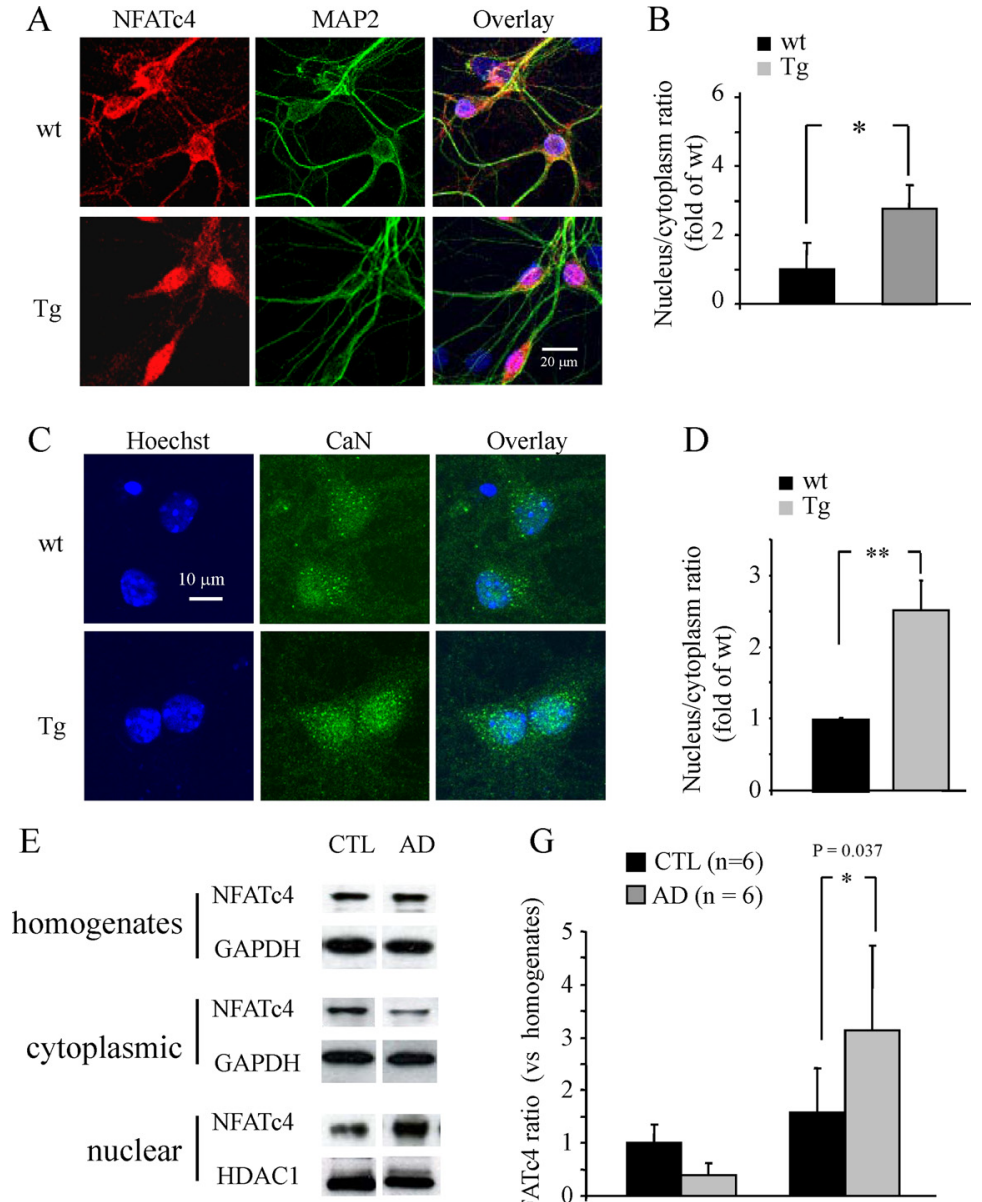

F
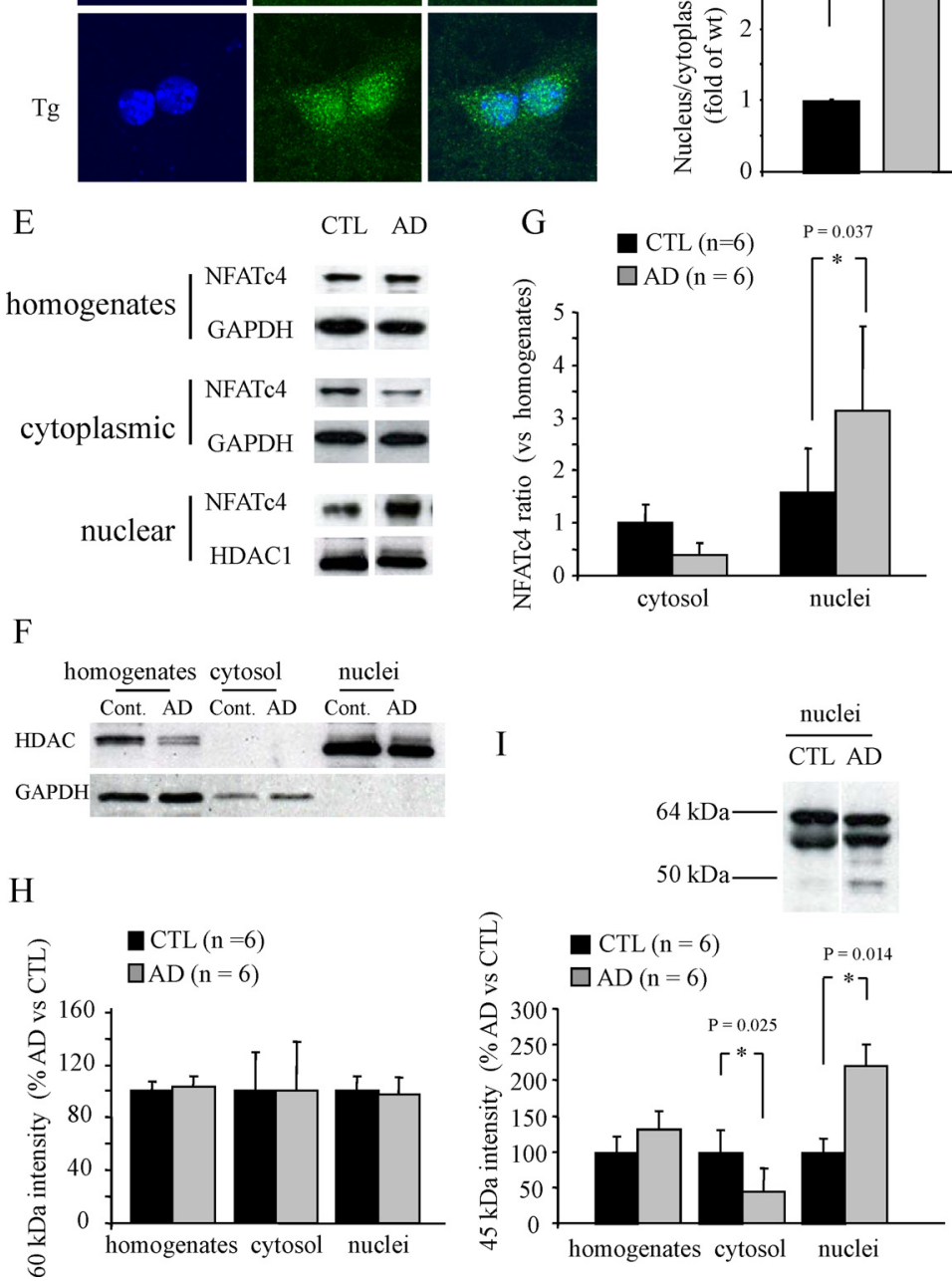

Figure 2. $A \beta$ induces NFATC4 and CaN-aberrant nuclear localization in Tg neurons in culture and AD postmortem brains. $A$, Immunostaining images of NFATC4 in Tg or wild-type neurons. Neurons from Tg or wild-type culture at 14 DIV are labeled with NFATc4 (red), MAP2 (green), and Hoechst nuclear counterstain (blue). Compared with wild-type neurons, Tg neurons show higher immunoreactivity of NFATc4 in the nuclei. $\boldsymbol{B}$, Quantification of NFATc 4 nuclear immunoreactivity obtained from $A . n=40$ cells from 3 different experiments. ${ }^{*} p<0.05$; data represent mean \pm SD. C, Immunostaining images of CaN in Tg or wild-type neurons. Neurons from Tg or wild-type culture at 14 DIV are labeled with CaN (green) and Hoechst nuclear counterstain (blue). Compared with wild-type neurons, Tg neurons show higher immunoreactivity of $\mathrm{CaN}$ in the nuclei. $\boldsymbol{D}$, Quantification of $\mathrm{CaN}$ nuclear immunoreactivity obtained from $C . n=40 .{ }^{*} p<0.01$; data represent mean $\pm S D$. $E, F$, Subcellular fractions were prepared from brains of AD patients or controls and analyzed by immunoblotting for NFATC4 and cytoplasmic or nuclear control proteins GAPDH and HDAC1, respectively. G, Semiquantification of NFATc4 immunoreactivity in $\boldsymbol{E}$. NFATc4 was detected in all three compartments but substantially enriched in nuclei in AD brains ( $n=6$ for each condition). ${ }^{*} p<0.05$; data represent mean $\pm S D$. $\boldsymbol{H}$, I, Semiquantification of immunoreactivity from each subcellular fraction for both full-length $\mathrm{CaN}(60 \mathrm{kDa})(\boldsymbol{H})$ and $\mathrm{CaNCA}(45 \mathrm{kDa})(I)$. Inset in $/$ shows representative blots of CaN in nuclear fraction. ${ }^{*} p<0.05$; data represent mean $\pm \mathrm{SEM}$. 
A

$\mathrm{A} 1_{1}$

प
$\square$ Full-length of hAKAP79, amino acid 1-427
Inhibitory peptide for CaN, amino acid 60-358
PKC binding residues, amino acid 31-52
CaN binding residues, amino acid 88-102
$\square$ PKA binding residues, amino acid 388-409

A2 AAV2-AKAP79 peptide construct ITR CMV/CBAp AKAP79 peptide WPRE ITR

B
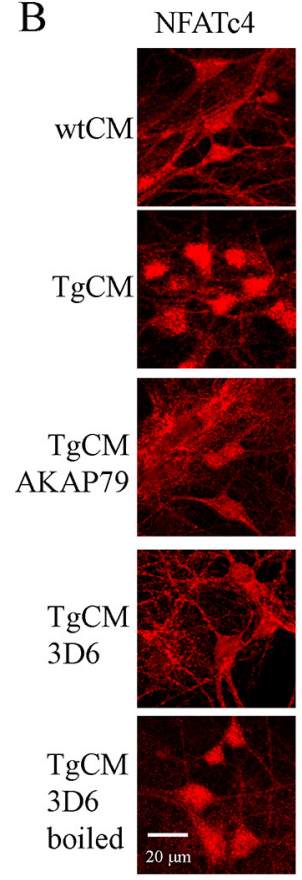

\section{-}

427

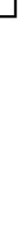

MAP2

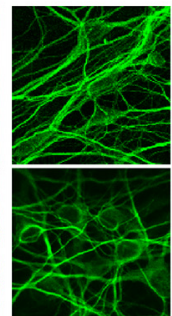

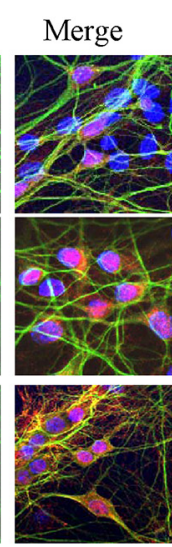

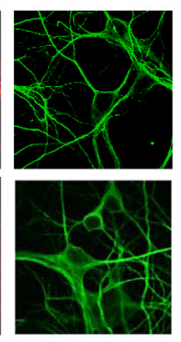

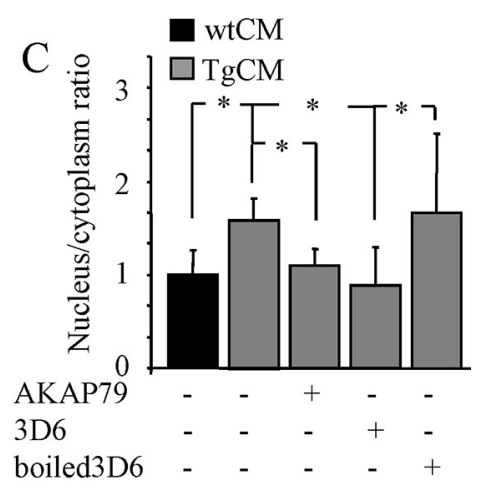

$\mathrm{D}$

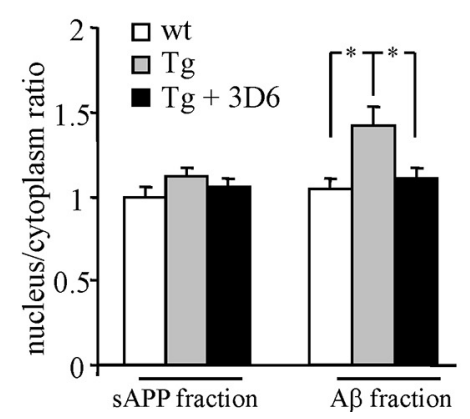

Figure 3. Conditioned medium induces NFATC4-aberrant nuclear translocation in wild-type cultured neurons. $A$, Schematic representation of AKAP79 inhibitory peptide for CaN (A1) and AAV2 viral vectors (AAV-CMV/CBA-WPRE) with AKAP79 inhibitory peptide (A2). B, A $\beta$ depletion or CaN inhibition with AKAP79 inhibitory peptide prevents TgCM-induced NFATc4 activation as seen in cultures stained with NFATc4 (red), MAP2 (green), and Hoechst nuclear counterstain (blue) from each experimental condition. C, Quantification of NFATc4-aberrant nuclear translocation induced by $\mathrm{TgCM}$ in wild-type cultured neurons. The ratio of nucleus to cytoplasm is shown. $\mathrm{TgCM}$ causes an increase in the nucleus/cytoplasm ratio of NFATC4 that is dependent on the presence of $A \beta$ (because anti-A $\beta$ antibody $3 D 6$ prevents the effect). Inhibition of CaN activation by AKAP79 peptide also prevented the increase in the nucleus/cytoplasm ratio of NFAT 4 ( $n>40$ cells). Data represent mean \pm SD. ${ }^{*} p<0.05$. D, Quantification of NFATc4-aberrant nuclear translocation induced by different SEC fractions in wild-type cultured neurons. Application of SEC fractions 6-7 (sAPP fraction) from either TgCM or wtCM caused no significant difference on the nucleus/cytoplasm ratio of NFATc4. However, application of SEC fractions 18-19 (A $\beta$ fraction) of TgCM onto wild-type neurons for $24 \mathrm{~h}$ caused significant increase in translocation of NFATC4 to the nucleus, but no changes were observed in neurons applied with the same SEC fractions of wtCM. Immunodepletion of A $\beta$ from the fractions $18-19$ of $\mathrm{TgCM}$ with 3D6 prevented the increase in the nucleus/cytoplasm ratio of NFATc4. $n>35$ cells. Data represent mean $\pm S D ;{ }^{*} p<0.05$. ITR, Inverted terminal repeat.

tory C-terminal domain and has been observed as a mechanism of CaN activation in stroke, trauma, and glaucoma (Morioka et al., 1999; Wu et al., 2004; Burkard et al., 2005; Huang et al., 2005). Together, the aberrant accumulation of nuclear NFATc4 and constitutively active form of CaN indicate aberrant activation of $\mathrm{CaN}-\mathrm{NFATc} 4$ signaling in AD. These results confirm the observation of truncated $\mathrm{CaN}$ in $\mathrm{AD}$ by Liu et al. (2005) but appear to contrast with those of Celsi et al. (2007) who observed diminished CaN immunoreactivity in neurons in $\mathrm{AD}$, perhaps because the latter study did not distinguish fulllength from truncated forms.
Conditioned media of Tg culture and $\mathrm{A} \boldsymbol{\beta}$ oligomers isolated by SEC induce NFATc4 nuclear translocation in wild-type neurons, which is blocked by $A \boldsymbol{\beta}$ immunodepletion or CaN inhibition

Soluble plaque-associated bioactive molecules, possibly assemblies of $\mathrm{A} \beta$, may be responsible for the "halo" effect of neuritic change and $\left[\mathrm{Ca}^{2+}\right]_{\mathrm{i}}$ alterations near plaques (Kuchibhotla et al., 2008; MeyerLuehmann et al., 2008; Koffie et al., 2009). To examine this possibility, we studied the effect of Tg neuronal culture conditioned medium on CaN activation and neurite properties of wild-type neurons. Wild-type cortical neurons were cultured in standard NB/B27 serum-free medium, and, at 14 $\mathrm{DIV}$, the medium was replaced with diluted 1:4 CM from wild-type or Tg cultures for $24 \mathrm{~h}$. As shown in Figure 3, $B$ and $C$, neurons treated with wtCM for $24 \mathrm{~h}$ exhibited a relatively low nucleus/cytoplasm ratio of NFATc4, which was similar to neurons in culture without CM replacement. In contrast, neurons treated with TgCM for $24 \mathrm{~h}$ demonstrated a significant increase in the nucleus/cytoplasm ratio of NFATc4 compared with neurons maintained in wtCM. The increased ratio was considerably reduced in neurons overexpressing an adeno-associated virus encoding an epitope-tagged (Flag) AKAP79 fragment (AAV-AKAP79), a potent CaN inhibitory peptide (Coghlan et al., 1995) (Fig. 3A). Immunodepletion of $\mathrm{A} \beta$ from the TgCM with 3D6 prevented the increase in the nucleus/cytoplasm ratio of NFATc4 (Fig. $3 B, C)$, suggesting that soluble $A \beta$ species in the TgCM-mediated activation of $\mathrm{CaN}$ and NFATc4 nuclear translocation. To better characterize the specific role of $\mathrm{A} \beta$ oligomers in CaN-mediated NFATc4 activation, nondenaturing SEC was used to isolate the various $\mathrm{A} \beta$ species from TgCM. Both ELISA and Western blot analysis showed that SEC fractions 17-20 of TgCM, but not the same fractions of wtCM, were markedly enriched in either oligomeric forms of $\mathrm{A} \beta_{40}$ and $\mathrm{A} \beta_{42}$ (supplemental Fig. 2E-G, available at www.jneurosci.org as supplemental material). Application of SEC fractions 18-19 (oligomeric A $\beta$ fraction) of TgCM onto wild-type neurons for $24 \mathrm{~h}$ caused a significant increase in translocation of NFATc4 to the nucleus, but no changes were observed in neurons treated with the same SEC fractions of wtCM. Immunodepletion of $A \beta$ from the fractions $18-19$ of TgCM with 3D6 prevented the increase in the nucleus/cytoplasm ratio of NFATc4 (Fig. 3D). Wild-type neurons treated with fractions 6-7 [soluble APP (sAPP) fraction] (supplemental Fig. $2 E-G$, available at www.jneurosci.org as supplemental material) from either TgCM or wtCM showed no significant difference in the nucleus/cytoplasm ratio of NFATc4. These results suggest that either $A \beta$ containing $C M$ from Tg culture 


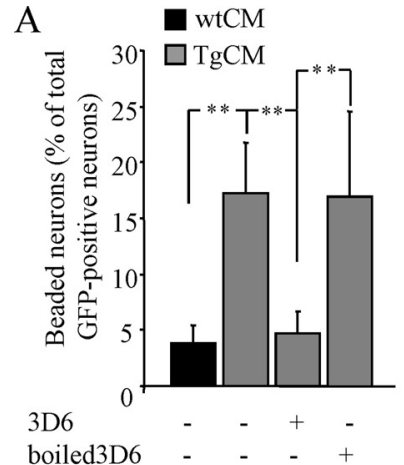

C

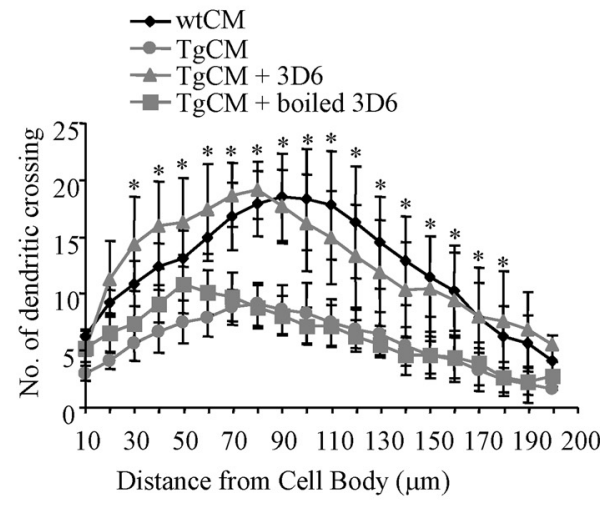

$\mathrm{E}$

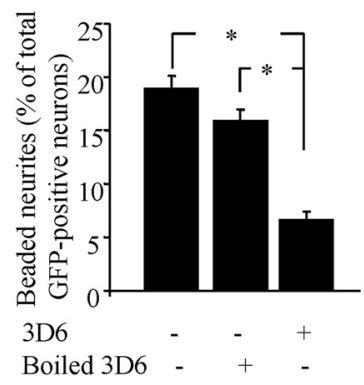

G

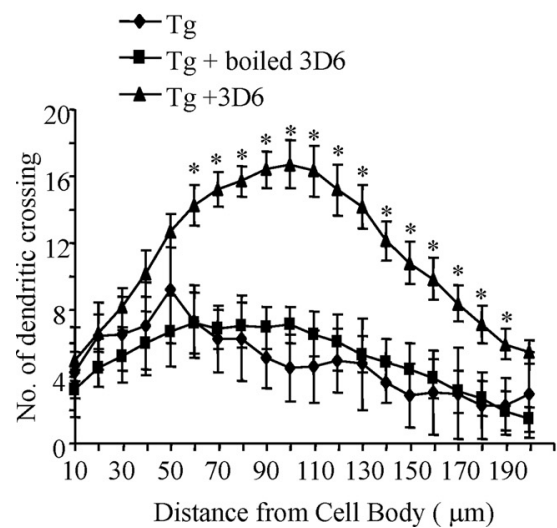

B
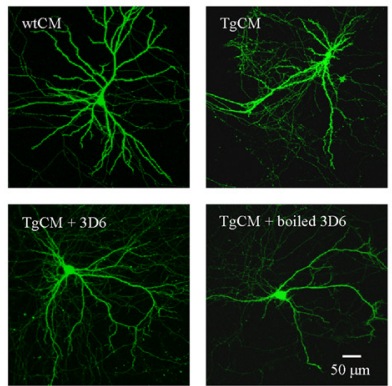

$\mathrm{D}$

wtCM

$\square \mathrm{TgCM}$
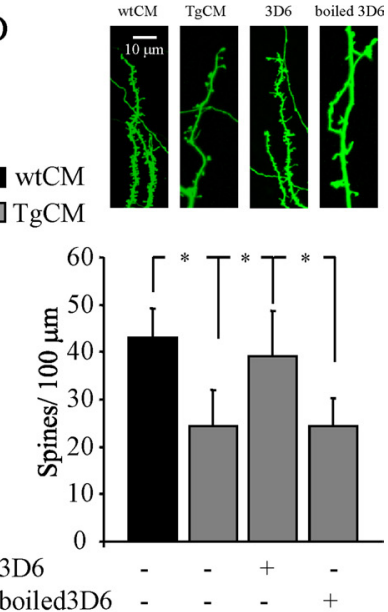

F

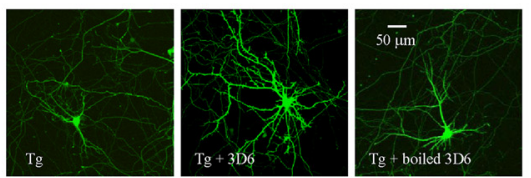

$\mathrm{H}$
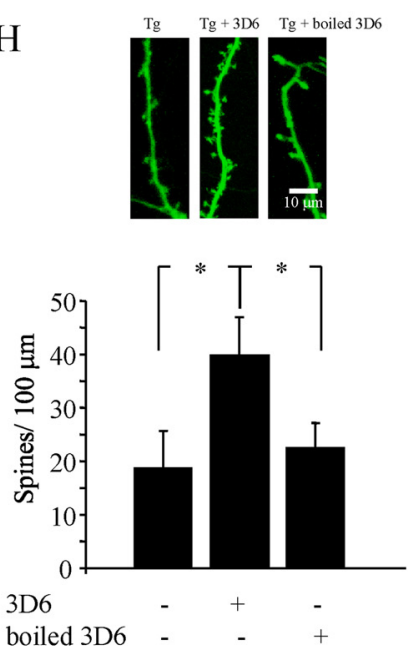

Figure 4. Aberrant neuronal morphologies induced by $\operatorname{Tg} C \mathrm{C}$ or APP overexpression are prevented by $\mathrm{A} \beta$ depletion. $A$, Primary cultures were maintained in $\mathrm{TgCM}$ for $21 \mathrm{DIV}$ in different culture conditions, as indicated. The percentage of neurons with dendritic dystrophies at 21 DIV is increased in the presence of $\mathrm{TgCM}$, and this beading can be prevented by immunodepletion of $A \beta . B, C$, Representative GFP-labeled mature neurons $(\boldsymbol{B})$ and Sholl analysis of branching on dendrites of neurons from indicated conditions shows that $\mathrm{TgCM}$ reduced branching and that this is rescued by immunodepletion of $\mathrm{A} \beta$ with $3 \mathrm{D} 6(\boldsymbol{C}$. D. Spine densities are determined in neurons without apparent dystrophies in each experimental condition, showing a decrease in spine density with $\mathrm{TgCM}$ that could be rescued with $3 \mathrm{D} 6$ treatment. $\boldsymbol{E}-\boldsymbol{H}, \mathrm{A} \beta$ depletion prevents APP overexpression-induced morphological abnormalities. In Tg cultures at 21 DIV, dendritic dystrophies $(\boldsymbol{E})$, dendritic attenuation $(\boldsymbol{F}, \boldsymbol{G})$ and spine loss $(\boldsymbol{H})$ are prevented by $A \beta$

or SEC-isolated A $\beta$ oligomers is capable of inducing CaN-mediated NFATc4 activation.

\section{$A \beta$ containing conditioned medium causes morphological abnormalities in wild-type neurons identical to those observed in Tg neurons in culture} To test whether the abnormal morphology observed in Tg cultures is caused by $\mathrm{A} \beta$, we examined wild-type cultured cortical neurons growing in either Tg or wildtype CM starting $24 \mathrm{~h}$ after plating and maintained in CM until neuron maturity (24 DIV). As shown in Figure 4A, wild-type cultures maintained in TgCM exhibited a significantly higher number of neurons with focal neuritic dystrophies compared with cultures maintained in wtCM. Cultures maintained in TgCM that was preimmunodepleted by 3D6, but not boiled 3D6, had a lower number of neurons with dystrophies similar to that seen in cultures growing in wtCM. Sholl analysis indicated that neurons growing in $A \beta$ containing $\mathrm{TgCM}$ also had dendritic simplification, but this is not the case in cultures maintained in TgCM that was immunodepleted by 3D6 (Fig. 4B,C). A striking effect of TgCM on dendritic spine density was also noted. The density of dendritic spines in the neurons growing in $\mathrm{TgCM}$ was greatly decreased (Fig. $4 D$ ). There was no significant reduction of spine density between neurons growing in wtCM and TgCM that was immunodepleted by 3D6, whereas spine density from neurons growing in $\mathrm{TgCM}$ that was treated with inactive, boiled 3D6 was also significantly reduced. In addition, $\mathrm{Tg}$ neurons grown in media immunodepleted with 3D6 at 3 DIV no longer developed dystrophic morphology during maturation. We detected no statistically significant difference in the number of neurons with dystrophies (Fig. 4E), dendritic complexity (Fig. $4 F, G$ ), or the mean spine density (Fig. $4 H$ ) between wild-type and Tg neurons treated with media that had been immunodepleted by 3D6. These results suggest that $\mathrm{A} \beta$ immunodepletion blocks neurodegenerative morphologies that occur in neurons exposed to $\mathrm{A} \beta$ containing $\mathrm{CM}$ or that overexpress APP.

depletion with 3D6. Sixty cells were analyzed per experimental condition in each experiment. ${ }^{*} p<0.05 ;{ }^{* *} p<0.01$; ${ }^{*} p<0.05$ in $\mathbf{G}$ (Tg with $3 \mathrm{D} 6$ vs Tg with boiled 3D6). Data represent mean $\pm S D$. 
A

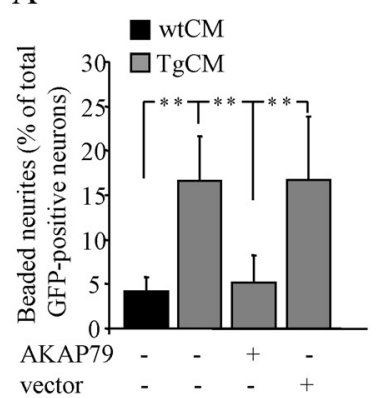

$\mathrm{C}$

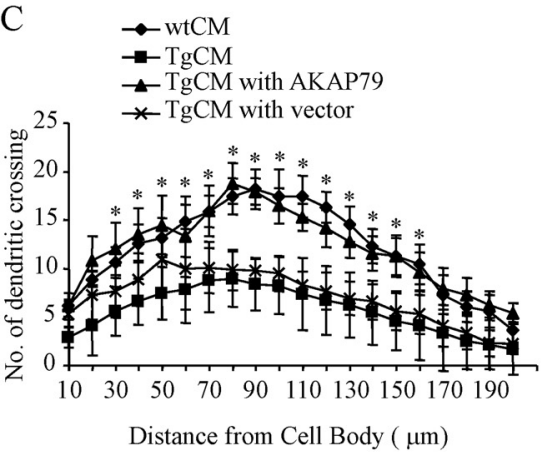

E

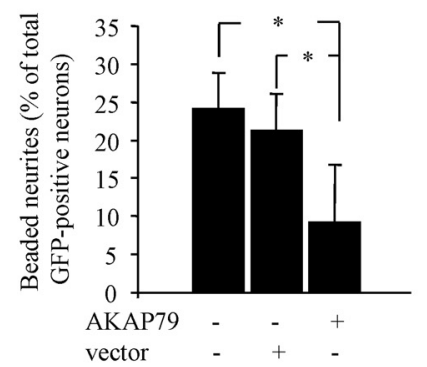

G

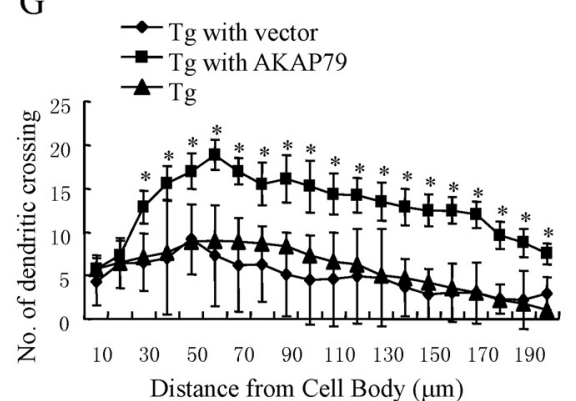

B

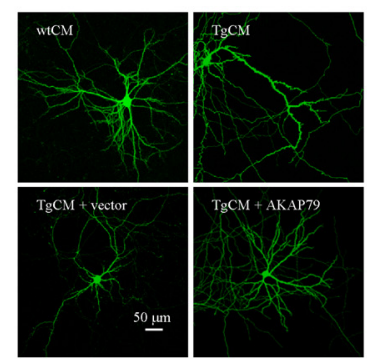

$\mathrm{D}$
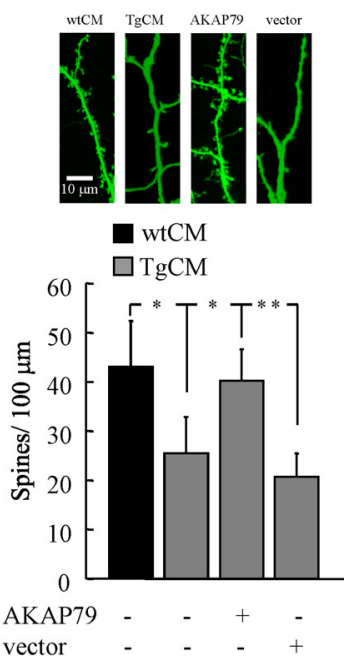

$\mathrm{F}$

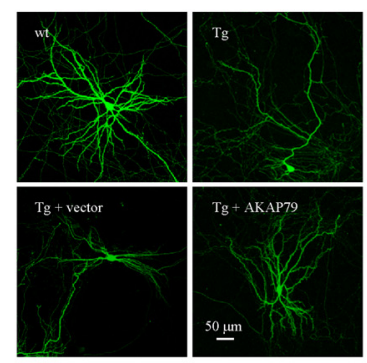

$\mathrm{H}$
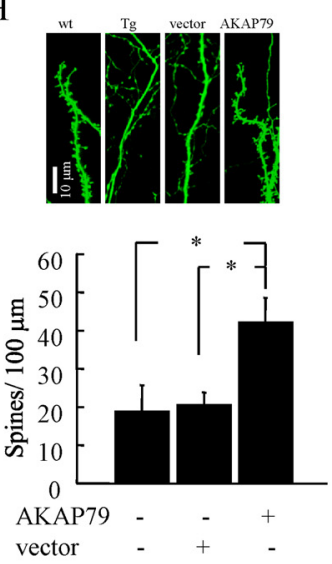

Figure 5. CaN inhibition by AKAP79 inhibitory peptide prevents TgCM-induced morphological abnormalities. Dendritic dystrophies $(\boldsymbol{A})$, dendritic attenuation $(\boldsymbol{B}, \boldsymbol{C})$, and spine loss $(\boldsymbol{D})$ in wild-type cultured neurons growing in $\mathrm{Tg} C \mathrm{C}$ are significantly prevented by CaN inhibitory peptide AKAP79. ${ }^{*} p<0.05$ in C (TgCM with AKAP79 vs TgCM with vector). ${ }^{* *} p<0.01$. Data are mean \pm SD from three independent experiments in triplicate. $\boldsymbol{E}-\boldsymbol{H}$, CaN inhibition by AKAP79 inhibitory peptide prevents APP overexpressioninduced morphological abnormalities. In Tg cultures at $21 \mathrm{DIV}$, dendritic dystrophies $(\boldsymbol{E})$, dendritic attenuation $(\boldsymbol{F}, \boldsymbol{G})$, and spine loss $(\boldsymbol{H})$ are prevented by CaN inhibitory peptide AKAP79. ${ }^{*} p<0.05$ in $\mathbf{G}$ (Tg with AKAP79 vs Tg with vector). Data are mean \pm SD from three independent experiments, each in triplicate.

Inhibition of either CaN activity or CaN-mediated NFAT activation abolishes $\mathrm{TgCM}$ or APP overexpression induced morphological abnormalities Both CaN-mediated NFATc4 activation and abnormal morphologies were detected in Tg neurons and in wild-type neurons growing in $\mathrm{TgCM}$. We reasoned that $\mathrm{A} \beta$ might cause the morphological changes via $\mathrm{CaN}$ activation or CaN activation and morphologic changes might each be unrelated effects of $\mathrm{A} \beta$ treatment. To address whether $\mathrm{CaN}$ is involved in the development of $\mathrm{A} \beta$-related abnormal morphologies, wild-type neurons growing in TgCM at 3 DIV were transduced with an AAV encoding a CaN inhibitory peptide AKAP79. At 14 DIV, essentially $100 \%$ of neurons expressed AKAP79 by measuring the colocalization of Flag-tagpositive neurons and MAP2-stained neurons (supplemental Fig. 3A, available at www.jneurosci.org as supplemental material). Tg neurons overexpressing AKAP79, but not a controlvector, $\mathrm{AAV}-\beta$-galactosidase, contained significantly fewer neurons with beaded processes at 21 DIV (Fig. 5A). AKAP79 overexpression abolished TgCM-induced dendritic simplification as assessed by Sholl analysis (Fig. $5 B, C$ ) and reduction in dendritic spine density (Fig. 5D). In addition, Tg neurons overexpressing AKAP79 inhibitory peptide at an early time point (3 DIV) no longer developed dystrophic morphology during maturation. We detected no statistically significant difference in the number of neurons with dystrophies (Fig. 5E), dendritic complexity (Fig. $5 F, G$ ), and the mean spine density (Fig. $5 H$ ) between wild-type and $\mathrm{Tg}$ neurons overexpressing AKAP79 inhibitory peptide. FK506, a potent inhibitor of CaN with an independent mechanism of action, also blocked TgCM-induced dendritic spine loss (supplemental Fig. 3B, available at www. jneurosci.org as supplemental material). These results suggest that $\mathrm{CaN}$ inhibition blocks neurodegenerative morphologies that occur in neurons exposed to $\mathrm{A} \beta$ containing $\mathrm{CM}$ or that overexpress APP.

CaN-mediated activation of NFAT has been demonstrated to play an important role in axonal outgrowth and activitydependent dendritic structural changes during development (Graef et al., 2003; Groth and Mermelstein, 2003; Schwartz et al., 2009). Our present study indicates that nuclear accumulation of NFATc4 occurs in neurons from $\mathrm{Tg}$ cultures and in human $\mathrm{AD}$ postmortem brain and that $\mathrm{A} \beta$ containing $\mathrm{CM}$ from $\mathrm{Tg}$ culture is capable of inducing CaN-mediated NFATc4 nu- 
clear localization in wild-type neurons. To clarify the signaling pathway activated by $\mathrm{CaN}$ that could involve $\mathrm{CaN}$-dependent morphological neurodegeneration during $\mathrm{A} \beta$ neurotoxicity, we examined the effect of 11R-VIVIT (VIVIT), a cell-permeable peptide that blocks the docking sites for CaN-NFAT interaction and therefore specifically inhibits CaN-mediated NFAT activation without impacting other $\mathrm{CaN}$ substrates (Aramburu et al., 1999). Application of $2 \mu \mathrm{M}$ VIVIT to wild-type neurons growing in TgCM abolished TgCMinduced NFAT nuclear accumulation (supplemental Fig. $3 C, D$, available at www.jneurosci.org as supplemental material) and blocked morphological deficits induced by $\mathrm{A} \beta$, including reduced numbers of neurons with dendritic dystrophies (Fig. 6A), increased dendritic complexity (Fig. $6 B, C$ ), and spine density (Fig. 6D). Similarly, Tg neurons treated with VIVIT showed dramatically improved morphology compared with $\mathrm{Tg}$ neurons treated with carrier (DMSO) (Fig. 6E-H). No significant changes in the number of neurons with dendritic dystrophies, dendritic processes, and spine density were detected in wild-type neurons treated with VIVIT or DMSO, suggesting that inhibition of CaN-NFAT interaction at the concentration that we are using does not have a strong effect on baseline maturation. Thus, inhibition of CaN-NFAT interaction and subsequent NFAT nuclear accumulation by VIVIT blocks TgCM or APP overexpression-induced morphological abnormalities in culture. These data indicate that upregulation of CaN activity by $\mathrm{A} \beta$ activates the NFAT cascade, resulting in a pathological triad of dendritic spine loss, dendritic simplification, and neuritic dystrophies.

Transduction of a CaNCA into wild-type cultured neurons induces abnormal morphology that is a phenocopy of the $A \boldsymbol{\beta}$ effect

To examine whether $\mathrm{CaN}$ activation is sufficient to cause these morphologic changes, even in the absence of overexpressed APP or exogenously applied $\mathrm{A} \beta$, we investigated whether the expression of a CaNCA would favor morphological changes in wild-type cultured neurons. An AAV vector encoding an HA-tagged CaNCA (AAV-CaNCA) or wild-type CaN (AAV-CaNwt) or an AAV vector control was expressed in cortical cultures. HA-tag immunostaining showed that nearly all MAP2-stained neurons expressed AAV-CaNwt or AAV-CaNCA, and neurons overexpressing CaNCA had significantly increased NFAT-luciferase activity,
A

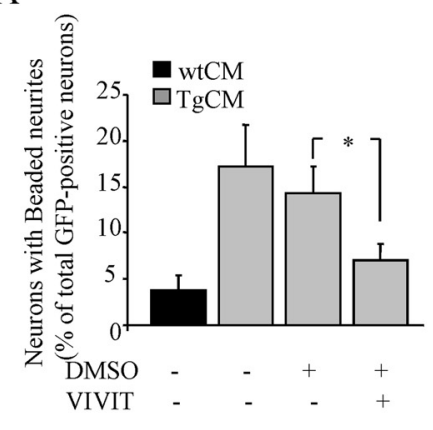

C

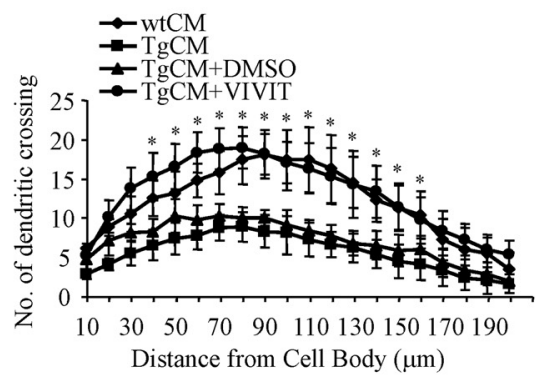

$\mathrm{E}$

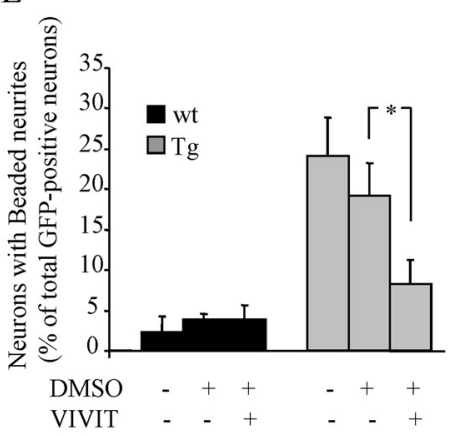

G

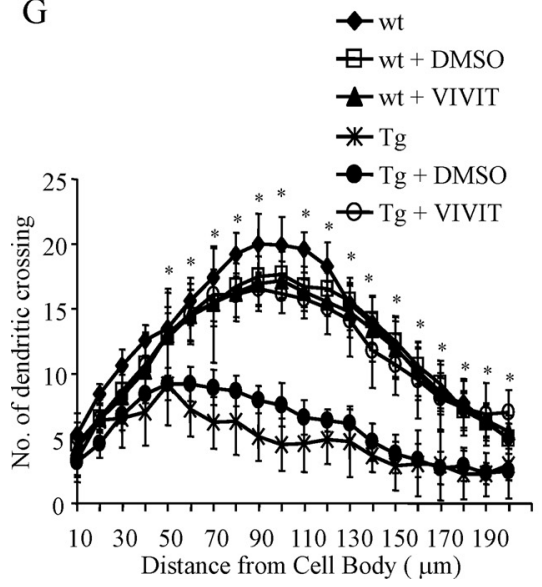

B

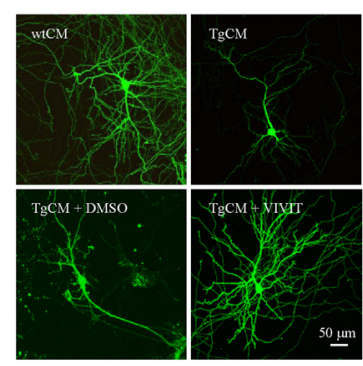

D

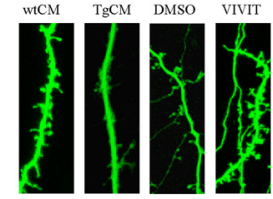

wtCM

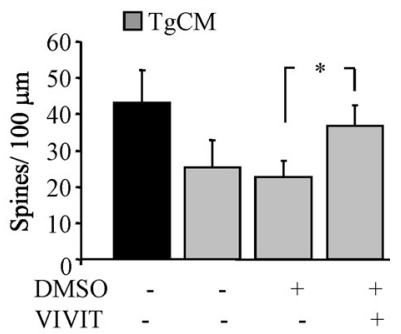

F

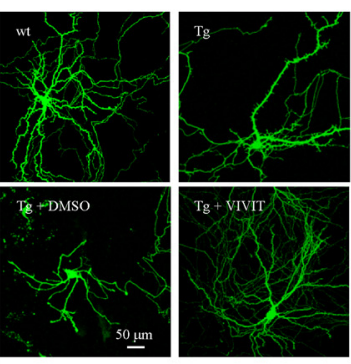

$\mathrm{H}$
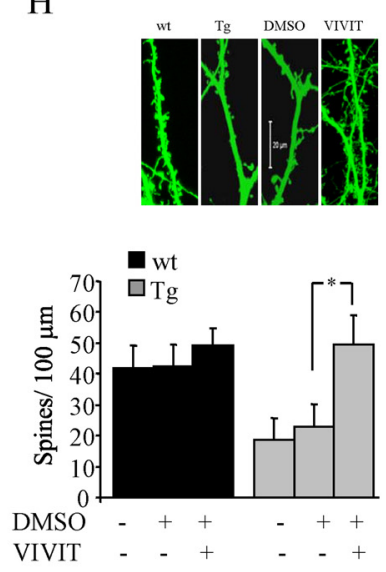

Figure 6. Inhibition of CaN-NFAT interaction by VIVIT prevents TgCM-induced morphological abnormalities. Dendritic dystrophies $(A)$, dendritic attenuation $(\boldsymbol{B}, \boldsymbol{C})$, and spine loss $(\boldsymbol{D})$ in wild-type cultured neurons growing in TgCM are significantly prevented by VIVIT (catalog \#480401; Calbiochem). ${ }^{*} p<0.05$ in C (TgCM with VIVIT vs TgCM with DMSO). Data are mean \pm SD from three independent experiments in triplicate. $\boldsymbol{E}-\boldsymbol{H}$, Inhibition of CaN-NFAT interaction by VIVIT prevents APP overexpression-induced morphological abnormalities. In Tg cultures at 21 DIV, dendritic dystrophies $(\boldsymbol{E})$, dendritic attenuation $(\boldsymbol{F}, \boldsymbol{G})$, and spine loss $(\boldsymbol{H})$ are prevented by VIVIT. ${ }^{*} p<0.05$ in $\boldsymbol{G}$ (Tg with VIVIT vs Tg with DMSO). Data are mean \pm SD from three independent experiments in triplicate. 
A

B
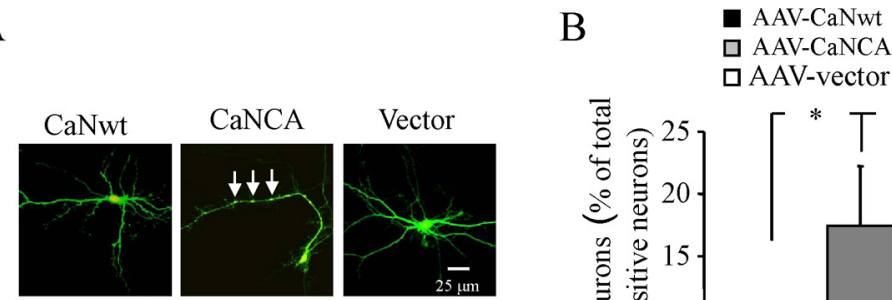

CA

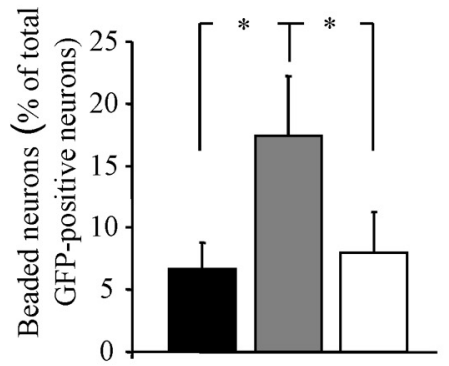

$\mathrm{C}$

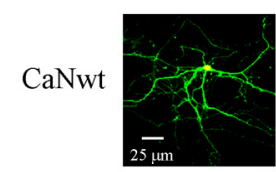

CaNCA

Vector

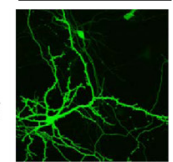

$\mathrm{D}$

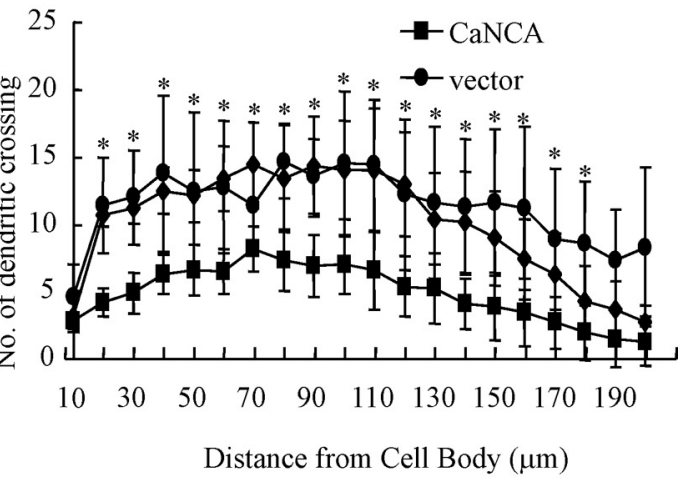

Distance from Cell Body $(\mu \mathrm{m})$

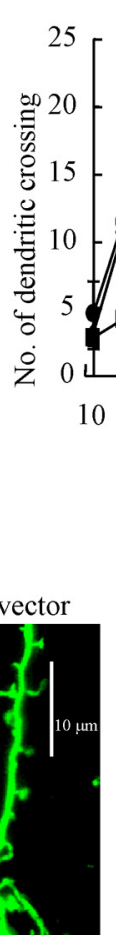

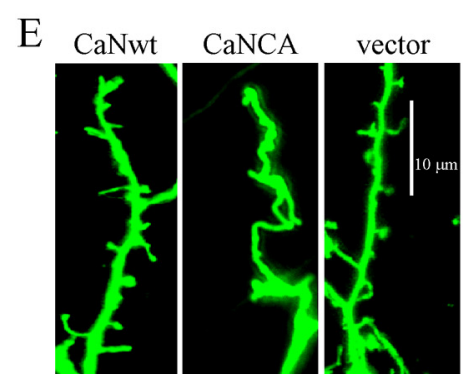

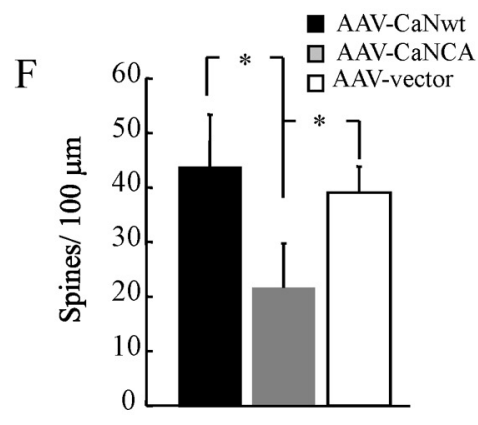

Figure 7. Wild-type cultured neurons overexpressing a constitutively active CaN construct, CaNCA, develop abnormal morphology that is a phenocopy of the $A \beta$ effect. Overexpression of $C$ aNCA, but not $C a N w$ tor vector control, into wild-type cultures induces dendritic dystrophies $(\boldsymbol{A}, \boldsymbol{B}$; arrows indicated local swelling of dendrites), simplification of dendritic arborization $(\boldsymbol{C}, \boldsymbol{D})$, and spine loss $(\boldsymbol{E}, \boldsymbol{F})$. Neurons expressing CaNCA displayed significantly more neurons with dendritic dystrophies, simplified dendritic complexity, and spine loss than either CaNwt or vector-expressing neurons. ${ }^{*} p<0.05 ;{ }^{*} p<0.05$ in $\boldsymbol{D}$ (CaNwt vs CaNCA). Data are mean \pm SD from three independent experiments, each in triplicate.

which was blocked by AKAP79 inhibitor peptide (supplemental Fig. $4 A, B$, available at www.jneurosci.org as supplemental material). As shown in Figure 7, $A$ and $B$, neurons with swollen dendrites were barely detectable in CaNwt-overexpressing cultures, but they were prominently detected in CaNCA-overexpressing cultures. Approximately $15 \%$ of total GFP-positive neurons were observed to have typical local neuritic dystrophies in cultures overexpressing CaNCA (Fig. 7A, B), whereas 6\% of total GFP-positive neurons developed dystrophies in CaNwt-expressing cultures. The latter is similar to the number of dystrophic neurites found in cultures expressing $\beta$-galactosidase, an AAV-vector control. Dendritic complexity (Fig. $7 C, D$ ) and mean spine density (Fig. $7 E, F$ ) were reduced in neurons overexpressing CaNCA but not in CaNwt- or vectoroverexpressing neurons. Inclusion of AKAP79 inhibitory peptide or VIVIT virtually eliminated CaNCA overexpressioninduced dendritic spine loss (supplemental Fig. 4C, available at www.jneurosci.org as supplemental material), suggesting that
NFAT activation is critical for CaNCAinduced dendritic spine loss. These data indicate that ectopic expression of CaNCA is sufficient to cause neuritic dystrophies, dendritic simplification, and spine loss in neurons in culture.

\section{CaNCA induces abnormal neuronal morphologies in vivo}

To investigate the role of elevated $\mathrm{CaN}$ activity on neuronal morphology in the intact adult mouse brain, we next introduced high-titer AAV-CaNCA, AAVCaNwt, or AAV- $\beta$-galactosidase, along with AAV-GFP, intracranially into the somatosensory cortex or hippocampus of C57BL/6J mice by stereotaxic injection, as described in Materials and Methods. Three to 4 weeks after intracranial injection, GFP-filled neurites and corresponding spines were detectable in the live animals using multiphoton microscopy (Fig. 8C) (Spires et al., 2005). GFP-labeled neurons were also observed in limited cortical and hippocampal areas in postmortem sections stained with a GFP antibody (Fig. 8A). We confirmed, with HAtag staining, that almost all of the GFPpositive cells were immunoreactive for CaNwt (or CaNCA), showing that GFPlabeled neurons also expressed CaNwt or CaNCA (supplemental Fig. 5A, available at www.jneurosci.org as supplemental material). Compared with neurons expressing control vector or CaNwt, CaNCA-expressing neurons showed high levels of NFATc4 nuclear distribution (supplemental Fig. 5A, available at www. jneurosci.org as supplemental material). The dendritic morphology of GFPlabeled neurites from cortical and hippocampal areas of wild-type mice injected with CaNCA displayed neurodegenerative alterations. Dystrophies were observed along the length of dendrites (Fig. 8 B2) or axons (Fig. 8B4), whereas dendrites or axons from these areas of mice injected with CaNwt showed normal processes (Fig. 8B1,B3), similar to those seen in vector control-injected mice. High-power images from multiphoton observations of the live brain allowed analysis of dendritic spines, which showed that, compared with the control, spine density was significantly decreased in mice injected with CaNCA, whereas CaNwt-injected mice showed mean spine density comparable with control vector-injected mice (Fig. 8C,D).

\section{Overexpression of a genetically encoded $\mathrm{CaN}$ inhibitor AKAP79 inhibitory peptide reduces $A \beta$ associated neurodegenerative alterations in vivo}

To directly determine the effect of $\mathrm{CaN}$ inhibition on the $\mathrm{A} \beta$ related morphological abnormalities in the adult rodent brain in vivo, AAV-AKAP79 inhibitory peptide or a vector control was coinjected with AAV-GFP into somatosensory cortex in 6-monthold living APP/PS1 mice. With multiphoton imaging, we were 
able to quantitatively compare neuritic dystrophies ( size of dystrophies defined as areas of swelling $>2.5 \mu \mathrm{m}$ in diameter), neurite curvature, as well as spine density near to $(<50 \mu \mathrm{m})$ or far from $(>50 \mu \mathrm{m})$ amyloid deposits in living APP/PS1 mice. As shown in Figure 9, the mean size of dystrophies near plaques from control vectorinjected brain was significantly larger than that found in brain injected with AKAP79 (Fig. 9A2,A3,B). Compared with the vector control, spine density was significantly increased near plaques in mice injected with AKAP79 inhibitory peptide (Fig. 9C).

Another well characterized morphological alteration in both APP overexpressing mouse brain and human $\mathrm{AD}$ is the development of tortuous, nonlinear trajectories for neurites, especially near plaques (Knowles et al., 1999; Le et al., 2001). This tortuosity is measured by "neuronal curvature," a marker of how straight a neurite segment is (Knowles et al., 1999). Compared with the elevated neuritic curvature seen at baseline in the APP/PS1 mice, we observed a significant improvement in neurite curvature in AKAP79 inhibitory peptide-injected mice (Fig. 9D). Both GFP and AKAP79 inhibitory peptide were coexpressed in the vast majority of neurons (supplemental Fig. 5B, available at www.jneurosci.org as supplemental material). Examination of $\mathrm{A} \beta$ deposits revealed no changes in the $\mathrm{A} \beta$ deposits themselves associated with AAV injection.

To exclude the possibility that in vivo imaging of GFP in neuritic dystrophies might not be representative, we examined SMI312 immunoreactivity, which recognizes a neurofilament protein that labels all axons, in postmortem sections. In the postmortem samples in control areas not expressing AKAP79 inhibitory peptide, axons in close proximity to $A \beta$ deposits had abnormal large dystrophies as expected (Fig. 9E1). In contrast, substantially fewer axons in the AKAP79 inhibitory peptideinjected areas in close proximity to $\mathrm{A} \beta \mathrm{de}$ posits showed dystrophies (Fig. 9E2,F). Consistent with the live imaging data, the mean size of dystrophies from control vector-injected brain was significantly larger than those found in areas injected with AKAP79 inhibitory peptide (data not shown). Together, these results show that $\mathrm{CaN}$ inhibition blocks the neurodegenerative changes that are well established to occur in the immediate vicinity of $\mathrm{A} \beta$ plaques in vivo, without affecting the $\mathrm{A} \beta$ deposits.

\section{Discussion}

Although it has been clear for a century that amyloid plaques are surrounded by
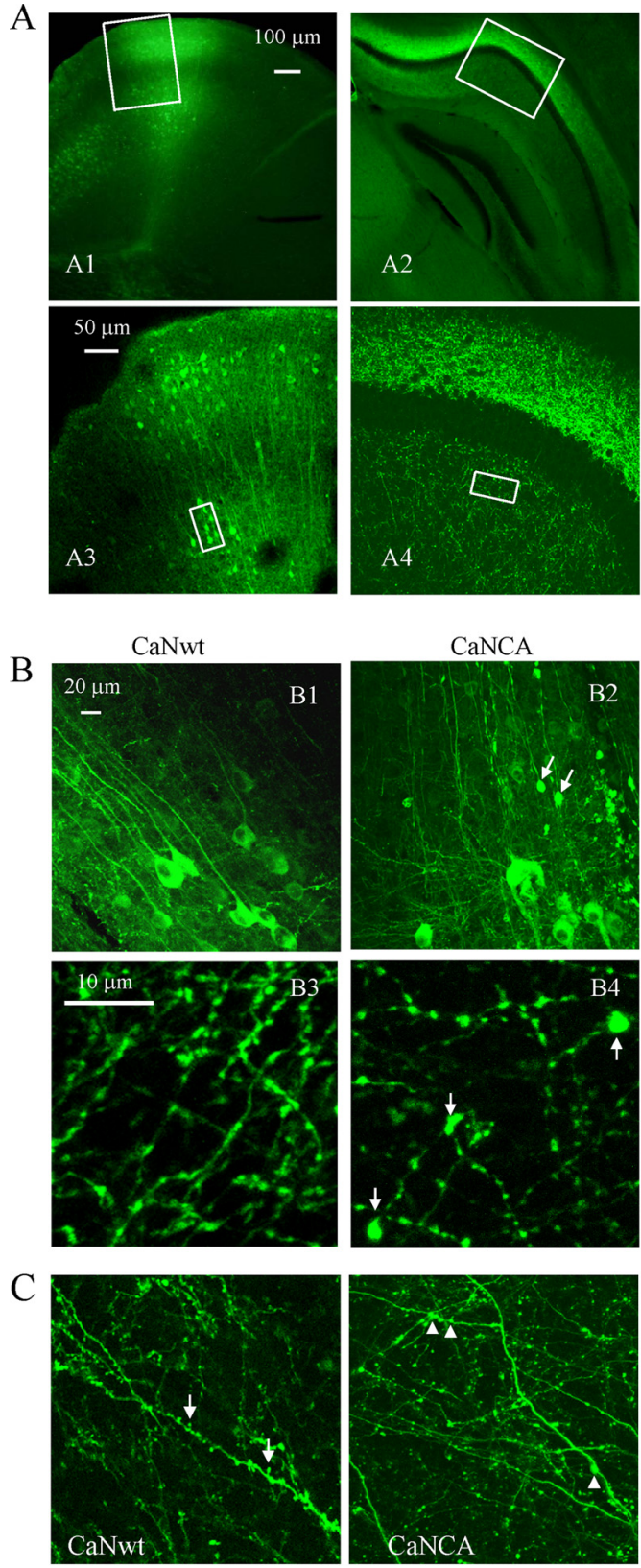

$\mathrm{D}$
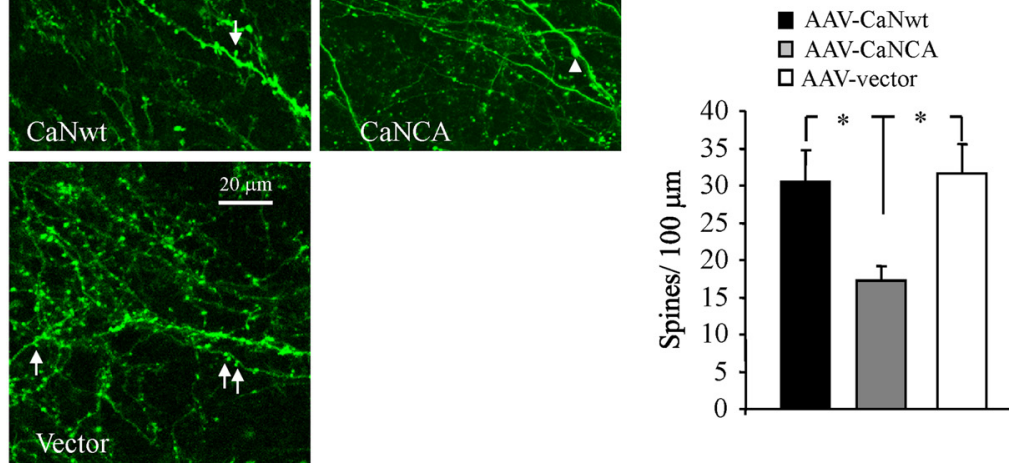

Figure 8. Overexpression of CaNCA, but not CaNwt, in the intact mouse brain induces abnormal morphologies. $\boldsymbol{A}$, Representative images in different magnifications from cortex $(\boldsymbol{A} \mathbf{1}, \boldsymbol{A} \mathbf{3})$ and hippocampal areas $(\boldsymbol{A} \mathbf{2}, \boldsymbol{A 4})$ after $\mathrm{CaNCA}$ or CaNwt transduction showing GFP expression in fixed postmortem brain sections stained with GFP antibody. $\boldsymbol{B}$, Representative high-power images of neuronal processes corresponding to areas indicated in $\boldsymbol{A}$ from $\mathrm{CaNwt}(\boldsymbol{B} 1, \boldsymbol{B} 3)$ or $\mathrm{CaNCA}(\boldsymbol{B} \mathbf{2}$, $B 4)$ injected mice. Arrows indicated neurites or axons with typical dystrophies. $C, D$, Images of dendritic spine $(\boldsymbol{C})$ and quantitative analysis of spine densities $(\boldsymbol{D})$ from live imaging of neurons without apparent dystrophies shows a decrease in spine density with CaNCA overexpression. In $\boldsymbol{C}$, arrows indicated spines, and arrowhead indicated neurites with typical dystrophies. ${ }^{*} p<0.05$; values represent mean $\pm S D$ ( $n=4$ animals for each condition and total $>400$ spines). 
A
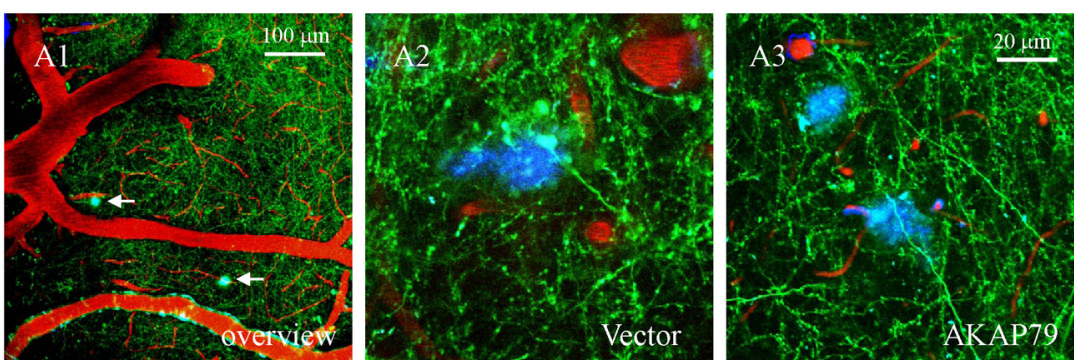

B

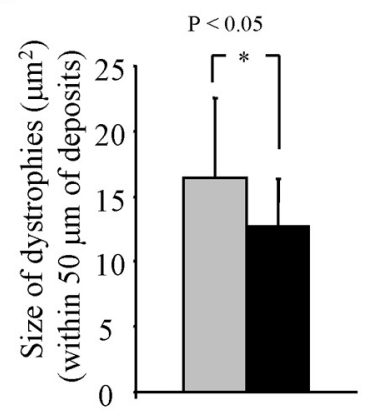

$\mathrm{C}$

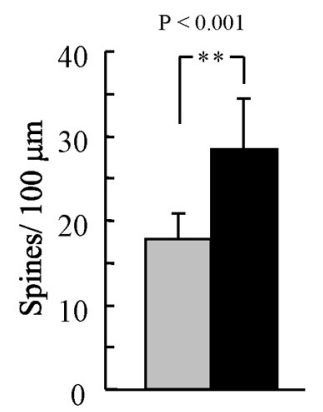

$\mathrm{D}$

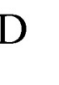

$\square$ Vector

- AKAP79

$\mathrm{P}=0.003$

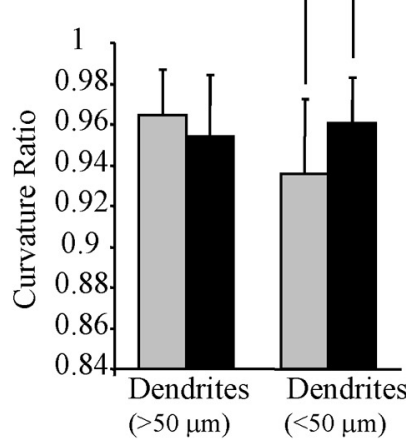

$\mathrm{E}$
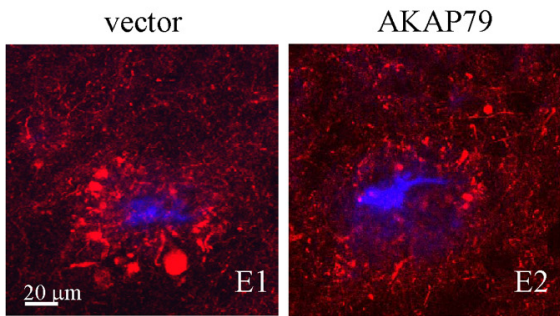

$\mathrm{F}$

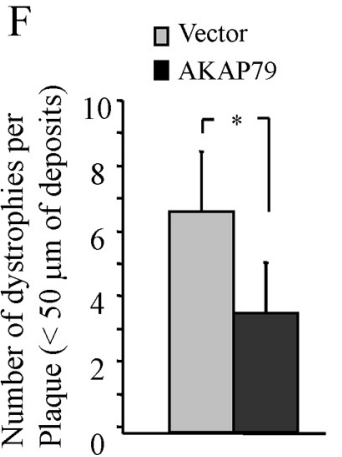

Figure 9. Abnormal morphologies are prevented by overexpression of CaN inhibitory peptide AKAP79 in APP/PS1 mouse brain A1, In vivo low-magnification image of GFP-expressing neurites and axons (green), blood vessels containing Texas Red, and amyloid deposition stained with methoxy- $\mathrm{XO}_{4}$ (blue). Arrows indicated $\mathrm{A} \beta$ deposits. $\mathbf{A 2}, \mathbf{A 3}$, High-magnification live images taken from $\sim 100 \mu \mathrm{m}$ below the brain surface in the neocortex of adult APP/PS1 mice show dendritic spines and dystrophies in both vector- and AKAP79-expressing conditions. $\boldsymbol{B}-\boldsymbol{D}$, Quantification of spine density $(\boldsymbol{B})$, dendritic dystrophies $(\boldsymbol{C})$, and neurite curvature $(\boldsymbol{D})$ near $A \beta$ deposits in vector- or AKAP79-expressing APP/PS1 mouse brain shows that AKAP79 expression decreases dystrophy size ( $\boldsymbol{B}$; vector, $16.4 \pm 6.1 \mu \mathrm{m}^{2} ;$ AKAP79, $12.8 \pm 3.6 ; p=0.029 ; n=45$ from 4 animals), increases spine density $(\boldsymbol{C}$; vector, $17.8 \pm 3.0 / 100 \mu \mathrm{m} ;$ AKAP79, $28.3 \pm 6.1 ; p<0.001 ; n>400$ spines), and decreases abnormal neurite curvature near plaques (D) ( $n=4$ animals for each condition and total $>400$ spines). $\boldsymbol{E}$, Postmortem sections indicated axonal dystrophies with SMI312 staining (red) and plaques with thioflavin $S$ (blue) shows that plaque-associated axonal dystrophies are reduced (quantified in $\boldsymbol{F}$; vector, $16.4 \pm 6.1 \mu \mathrm{m}^{2}$; AKAP79, $12.8 \pm 3.6 ; p=0.0291 ; n=45$ plaques from 4 animals) in areas injected with AKAP79. $F$, Quantification of numbers of axonal dystrophies per single $A \beta$ deposits from postmortem sections. Values represent mean $\pm S D .{ }^{*} p<0.05 ;{ }^{* *} p<0.01$.

neuritic abnormalities and the amyloid hypothesis of $\mathrm{AD}$ suggests that $\mathrm{A} \beta$ peptide induces downstream neurodegenerative changes leading ultimately to collapse of neural networks and clinical dementia (Hardy and Allsop, 1991; Hardy and Selkoe, 2002), the molecules and mechanisms underlying the translation of $A \beta$ neurotoxicity into morphological disruption remain undefined. Here we present data that support the idea that activation of CaN and subsequent NFAT-mediated downstream cascades are key molecular mechanisms linking $\mathrm{A} \beta$ to damage of the structural underpinnings of neural networks. This molecular model of neuronal degeneration is initiated by $\mathrm{A} \beta$-inducing calcium influx and $\mathrm{CaN}$ activation, which causes NFAT nuclear

accumulation, leading to a pathological triad of dendritic spine loss, dendritic simplification, and neuritic dystrophies. Importantly, we show reversal of morphological neurodegenerative phenotypes in vitro and in vivo with a neuroprotective strategy of CaN inhibition, providing an important proof in principle of a non- $\mathrm{A} \beta$ directed therapeutic intervention that improves neuronal structure in an $\mathrm{AD}$ model.

Memory loss in $\mathrm{AD}$ patients is correlated strongly with synaptic dysfunction (DeKosky and Scheff, 1990; Terry et al., 1991; Sze et al., 1997). CaN is a protein phosphatase that plays a fundamental role in memory formation through mechanisms controlling synaptic function (Malleret et al., 2001; Winder and Sweatt, 2001; Mansuy, 2003). Mice with inducible, hippocampal-restricted overexpression of CaNCA exhibit pronounced spatial learning and memory deficits in the Morris water maze task (Mansuy, 2003). The defect of learning behaviors is reversible in transgenic mice expressing a $\mathrm{CaN}$ inhibitory domain or application of antisense oligonucleotides (Malleret et al., 2001; Mansuy, 2003). These results suggest that synaptic dysfunction and memory retention deficits that occur in $\mathrm{AD}$ patients and animal $\mathrm{AD}$ models may result, at least in part, from altered $\mathrm{CaN}$ activity. Indeed, $\mathrm{CaN}$ inhibition with FK506 has been reported to improve memory function in APP transgenic mice (Dineley et al., 2007; Taglialatela et al., 2009).

In the present study, we have shown that neurons from Tg cultures exhibit increased NFATc4 nuclear translocation (Fig. 2A,B), which is known to be regulated by CaN activation. The NFATc4aberrant nuclear localization can also be induced by $\mathrm{TgCM}$, which contains high levels of naturally secreted $\mathrm{A} \beta$, and this can be blocked by immunodepletion of the TgCM with an $\mathrm{A} \beta$-specific antibody, by the potent $\mathrm{CaN}$ inhibitory peptide AKAP79, or by treatment with VIVIT, which blocks NFAT activation (Fig. $3 B, C$ ) (supplemental Fig. $3 C, D$, available at www.jneurosci.org as supplemental material). Importantly, the NFATc4aberrant nuclear localization and a constitutively active form of $\mathrm{CaN}$ were also found in $\mathrm{AD}$ postmortem brain, indicating that $\mathrm{CaN}$ activation and the resulting downstream NFAT transcriptional cascade also occurs in $\mathrm{AD}$. Moreover, in cultures, $\mathrm{CaN}$ inhibition or blockade of NFAT activation using VIVIT provided significant neuroprotection from TgCM or APP overexpressioninduced morphological deficits (Figs. 5, 6).

$\mathrm{CaN}$ activation has profound effects on neuronal morphology. We show, in both cultures and wild-type adult mouse brain in vivo, that manipulation of $\mathrm{CaN}$ activity by ectopic expression of CaNCA is sufficient to cause segmental spine loss, dendritic simplification, and focal swelling similar to $\mathrm{A} \beta$-induced mor- 
phological aberrations (Figs. 7, 8). In mouse models of AD, CaN inhibition potently reduces the $\mathrm{A} \beta$-related morphological neurodegenerative changes that occur near plaques (Fig. 9). These data suggest a pivotal novel role of $\mathrm{CaN}$ activation and CaNmediated NFAT signaling pathway in $\mathrm{A} \beta$-related morphological neurodegeneration, providing a mechanistic link between calcium overload, activation of $\mathrm{CaN}$, and $\mathrm{A} \beta$-induced neuronal morphological destruction of neural systems.

There are three major implications of these studies. First, our results confirm that $\mathrm{A} \beta$ induces $\mathrm{CaN}$ activation in vitro and in $\mathrm{AD}$ (Liu et al., 2005; Snyder et al., 2005; Hsieh et al., 2006; Agostinho et al., 2008; Reese et al., 2008; Abdul et al., 2009); we now show that CaN activation in neurons causes the pathological triad of dendritic spine loss, dendritic simplification, and dystrophies. Although it seems likely that activation of $\mathrm{CaN}$ has multiple effects, including functions at the dendritic spine itself (Hsieh et al., 2006), and it remains possible that VIVIT disrupts CaN functions other than NFAT dephosphorylation (Oliveria et al., 2007), our data are consistent with the possibility that NFAT-mediated cascades play a prominent role in the neurodegenerative process. These results clearly implicate a soluble form of $\mathrm{A} \beta$, likely oligomeric, as the responsible bioactive molecule that is present in the vicinity of plaques that mediates the neuronal alterations that occur within a halo near plaques (Koffie et al., 2009). Importantly, these results allow the development of a simple in vitro model of $\mathrm{A} \beta$-induced neurodegeneration ( $\mathrm{TgCM}$ treatment of wild-type neurons for $24 \mathrm{~h}$ ) that has predictive value for plaque-induced neurodegeneration in 8- to 12-month-old transgenic animals.

Second, activated CaN produces a phenocopy of these $\mathrm{A} \beta$ effects. Importantly, immunodepletion of $\mathrm{A} \beta$, inhibition of $\mathrm{CaN}$, or blockade of NFAT alone can inhibit these changes and lead to recovery of neuronal structure. Previous studies have shown some recovery of neuronal lesions after treatment with antibodies directed against $\mathrm{A} \beta$ (Lombardo et al., 2003; Brendza et al., 2005; Spires-Jones et al., 2008). Because our current data show that $\mathrm{CaN}$ activation is downstream of soluble $\mathrm{A} \beta$ neurotoxic effects, it seems likely that a strategy aimed at preventing or restoring $\mathrm{CaN}$-mediated neural system damage, combined with approaches that reduce $\mathrm{A} \beta$ generation or promote its clearance, may be more effective than either strategy alone. The higher enrichment of activated $\mathrm{CaN}$ and NFATc4 in the nuclear fraction of cortex from $\mathrm{AD}$ patients (Fig. $2 E-I$ ) reinforces the importance and disease relevance of these observations. Thus, CaN inhibition or blockade of NFAT or its targets may be an important avenue for consideration in $\mathrm{AD}$ therapeutics.

Third, our results suggest for the first time that $\mathrm{CaN}$ and NFAT play a major role in sculpting neural systems in the mature brain, implying that the adult brain is not "hardwired." A prominent role for $\mathrm{CaN}$ has been long established in learning and memory (Malleret et al., 2001; Winder and Sweatt, 2001; Zeng et al., 2001; Mansuy, 2003), and CaN activation is important in phenomena such as long-term depression. A recent study suggests that CaN-NFAT signaling is responsible for dendritic simplification during developmental pruning of the Xenopus neural system (Schwartz et al., 2009). However, a major role for CaNNFAT-mediated transcriptional events in dendrite remodeling in the adult brain or in disease conditions as observed here has not been reported previously. Because aberrant $\mathrm{CaN}$ activation has been implicated in CNS trauma, ischemia, kainate injury, and glaucoma (Morioka et al., 1999; Springer et al., 2000; Wu et al., 2004; Huang et al., 2005; Uchino et al., 2008), each of which leads to neural system degeneration, we postulate that the type of structural remodeling and morphological degenerative changes observed in multiple conditions might be a consequence of $\mathrm{CaN}$ activation. Intriguingly, it appears as if the major effects of $\mathrm{CaN}$ in $\mathrm{AD}$ may be mediated by NFAT, implying a potential unexplored role for transcriptional cascades in these conditions. Thus, a molecular mechanism of neurodegeneration in $\mathrm{AD}$ may be $\mathrm{A} \beta$-induced aberrant activation of a potent NFAT-mediated developmental program of neural system remodeling, suggesting possible therapeutic avenues for rescue.

\section{References}

Abdul HM, Sama MA, Furman JL, Mathis DM, Beckett TL, Weidner AM, Patel ES, Baig I, Murphy MP, LeVine H 3rd, Kraner SD, Norris CM (2009) Cognitive decline in Alzheimer's disease is associated with selective changes in calcineurin/NFAT signaling. J Neurosci 29:12957-12969.

Agostinho P, Lopes JP, Velez Z, Oliveira CR (2008) Overactivation of calcineurin induced by amyloid-beta and prion proteins. Neurochem Int 52:1226-1233.

Aramburu J, Yaffe MB, López-Rodríguez C, Cantley LC, Hogan PG, Rao A (1999) Affinity-driven peptide selection of an NFAT inhibitor more selective than cyclosporin A. Science 285:2129-2133.

Bacskai BJ, Hickey GA, Skoch J, Kajdasz ST, Wang Y, Huang GF, Mathis CA, Klunk WE, Hyman BT (2003) Four-dimensional multiphoton imaging of brain entry, amyloid binding, and clearance of an amyloid-beta ligand in transgenic mice. Proc Natl Acad Sci U S A 100:12462-12467.

Berridge MJ, Lipp P, Bootman MD (2000) The versatility and universality of calcium signalling. Nat Rev Mol Cell Biol 1:11-21.

Bezprozvanny I, Mattson MP (2008) Neuronal calcium mishandling and the pathogenesis of Alzheimer's disease. Trends Neurosci 31:454-463.

Brendza RP, Bacskai BJ, Cirrito JR, Simmons KA, Skoch JM, Klunk WE, Mathis CA, Bales KR, Paul SM, Hyman BT, Holtzman DM (2005) AntiAbeta antibody treatment promotes the rapid recovery of amyloidassociated neuritic dystrophy in PDAPP transgenic mice. J Clin Invest 115:428-433.

Burkard N, Becher J, Heindl C, Neyses L, Schuh K, Ritter O (2005) Targeted proteolysis sustains calcineurin activation. Circulation 111:1045-1053.

Busche MA, Eichhoff G, Adelsberger H, Abramowski D, Wiederhold KH, Haass C, Staufenbiel M, Konnerth A, Garaschuk O (2008) Clusters of hyperactive neurons near amyloid plaques in a mouse model of Alzheimer's disease. Science 321:1686-1689.

Celsi F, Svedberg M, Unger C, Cotman CW, Carrì MT, Ottersen OP, Nordberg A, Torp R (2007) Beta-amyloid causes downregulation of calcineurin in neurons through induction of oxidative stress. Neurobiol Dis 26:342-352.

Coghlan VM, Perrino BA, Howard M, Langeberg LK, Hicks JB, Gallatin WM, Scott JD (1995) Association of protein kinase A and protein phosphatase 2B with a common anchoring protein. Science 267:108-111.

DeKosky ST, Scheff SW (1990) Synapse loss in frontal cortex biopsies in Alzheimer's disease: correlation with cognitive severity. Ann Neurol 27:457-464.

Dineley KT, Hogan D, Zhang WR, Taglialatela G (2007) Acute inhibition of calcineurin restores associative learning and memory in Tg2576 APP transgenic mice. Neurobiol Learn Mem 88:217-224.

Geula C, Wu CK, Saroff D, Lorenzo A, Yuan M, Yankner BA (1998) Aging renders the brain vulnerable to amyloid beta-protein neurotoxicity. Nat Med 4:827-831.

Graef IA, Wang F, Charron F, Chen L, Neilson J, Tessier-Lavigne M, Crabtree GR (2003) Neurotrophins and netrins require calcineurin/NFAT signaling to stimulate outgrowth of embryonic axons. Cell 113:657-670.

Groth RD, Mermelstein PG (2003) Brain-derived neurotrophic factor activation of NFAT (nuclear factor of activated T-cells)-dependent transcription: a role for the transcription factor NFATc4 in neurotrophin-mediated gene expression. J Neurosci 23:8125-8134.

Grynkiewicz G, Poenie M, Tsien RY (1985) A new generation of $\mathrm{Ca}^{2+}$ indicators with greatly improved flourescence properties. J Biol Chem 260: 3440-3450

Halpain S, Hipolito A, Saffer L (1998) Regulation of F-actin stability in dendritic spines by glutamate receptors and calcineurin. J Neurosci 18:9835-9844.

Hardy J, Allsop D (1991) Amyloid deposition as the central event in the aetiology of Alzheimer's disease. Trends Pharmacol Sci 12:383-388.

Hardy J, Selkoe DJ (2002) The amyloid hypothesis of Alzheimer's disease: progress and problems on the road to therapeutics. Science 297:353-356. 
Hsiao K, Chapman P, Nilsen S, Eckman C, Harigaya Y, Younkin S, Yang F, Cole G (1996) Correlative memory deficits, Abeta elevation, and amyloid plaques in transgenic mice. Science 274:99-102.

Hsieh H, Boehm J, Sato C, Iwatsubo T, Tomita T, Sisodia S, Malinow R (2006) AMPAR removal underlies Abeta-induced synaptic depression and dendritic spine loss. Neuron 52:831-843.

Huang W, Fileta JB, Dobberfuhl A, Filippopolous T, Guo Y, Kwon G, Grosskreutz CL (2005) Calcineurin cleavage is triggered by elevated intraocular pressure, and calcineurin inhibition blocks retinal ganglion cell death in experimental glaucoma. Proc Natl Acad Sci U S A 102: 12242-12247.

Johnson-Wood K, Lee M, Motter R, Hu K, Gordon G, Barbour R, Khan K, Gordon M, Tan H, Games D, Lieberburg I, Schenk D, Seubert P, McConlogue L (1997) Amyloid precursor protein processing and A beta42 deposition in a transgenic mouse model of Alzheimer disease. Proc Natl Acad Sci U S A 94:1550-1555.

Klee CB, Crouch TH, Krinks MH (1979) Calcineurin: a calcium- and calmodulin-binding protein of the nervous system. Proc Natl Acad Sci U S A 76:6270-6273.

Klunk WE, Bacskai BJ, Mathis CA, Kajdasz ST, McLellan ME, Frosch MP, Debnath ML, Holt DP, Wang Y, Hyman BT (2002) Imaging Abeta plaques in living transgenic mice with multiphoton microscopy and methoxy-X04, a systemically administered Congo red derivative. J Neuropathol Exp Neurol 61:797-805.

Knowles RB, Wyart C, Buldyrev SV, Cruz L, Urbanc B, Hasselmo ME, Stanley HE, Hyman BT (1999) Plaque-induced neurite abnormalities: implications for disruption of neural networks in Alzheimer's disease. Proc Natl Acad Sci U S A 96:5274-5279.

Koffie RM, Meyer-Luehmann M, Hashimoto T, Adams KW, Mielke ML, Garcia-Alloza M, Micheva KD, Smith SJ, Kim ML, Lee VM, Hyman BT, Spires-Jones TL (2009) Oligomeric amyloid beta associates with postsynaptic densities and correlates with excitatory synapse loss near senile plaques. Proc Natl Acad Sci U S A 106:4012-4017.

Kuchibhotla KV, Goldman ST, Lattarulo CR, Wu HY, Hyman BT, Bacskai BJ (2008) Abeta plaques lead to aberrant regulation of calcium homeostasis in vivo resulting in structural and functional disruption of neuronal networks. Neuron 59:214-225.

Le R, Cruz L, Urbanc B, Knowles RB, Hsiao-Ashe K, Duff K, Irizarry MC, Stanley HE, Hyman BT (2001) Plaque-induced abnormalities in neurite geometry in transgenic models of Alzheimer disease: implications for neural system disruption. J Neuropathol Exp Neurol 60:753-758.

Liu F, Grundke-Iqbal I, Iqbal K, Oda Y, Tomizawa K, Gong CX (2005) Truncation and activation of calcineurin A by calpain I in Alzheimer disease brain. J Biol Chem 280:37755-37762.

Lombardo JA, Stern EA, McLellan ME, Kajdasz ST, Hickey GA, Bacskai BJ, Hyman BT (2003) Amyloid- $\beta$ antibody treatment leads to rapid normalization of plaque-induced neuritic alterations. J Neurosci 23:10879- 10883.

Lorenzo A, Yankner BA (1994) Beta-amyloid neurotoxicity requires fibril formation and is inhibited by congo red. Proc Natl Acad Sci U S A 91:12243-12247.

Malleret G, Haditsch U, Genoux D, Jones MW, Bliss TV, Vanhoose AM, Weitlauf C, Kandel ER, Winder DG, Mansuy IM (2001) Inducible and reversible enhancement of learning, memory, and long-term potentiation by genetic inhibition of calcineurin. Cell 104:675-686.

Mansuy IM (2003) Calcineurin in memory and bidirectional plasticity. Biochem Biophys Res Commun 311:1195-1208.

Mattson MP (2004) Pathways towards and away from Alzheimer's disease. Nature 430:631-639.

Meyer-Luehmann M, Spires-Jones TL, Prada C, Garcia-Alloza M, de Calignon A, Rozkalne A, Koenigsknecht-Talboo J, Holtzman DM, Bacskai BJ, Hyman BT (2008) Rapid appearance and local toxicity of amyloid-beta plaques in a mouse model of Alzheimer's disease. Nature 451:720-724.

Morioka M, Hamada J, Ushio Y, Miyamoto E (1999) Potential role of calcineurin for brain ischemia and traumatic injury. Prog Neurobiol 58:1-30.

Mulkey RM, Endo S, Shenolikar S, Malenka RC (1994) Involvement of a calcineurin/inhibitor-1 phosphatase cascade in hippocampal long-term depression. Nature 369:486-488.

Oliveria SF, Dell'Acqua ML, Sather WA (2007) AKAP79/150 anchoring of calcineurin controls neuronal L-type $\mathrm{Ca}^{2+}$ channel activity and nuclear signaling. Neuron 55:261-275.

Palotás A, Kálmán J, Palotás M, Juhász A, Janka Z, Penke B (2002) Fibroblasts and lymphocytes from Alzheimer patients are resistant to beta- amyloid-induced increase in the intracellular calcium concentration. Prog Neuropsychopharmacol Biol Psychiatry 26:971-974.

Pike CJ, Burdick D, Walencewicz AJ, Glabe CG, Cotman CW (1993) Neurodegeneration induced by $\beta$-amyloid peptides in vitro: the role of peptide assembly state. J Neurosci 13:1676-1687.

Reese LC, Zhang W, Dineley KT, Kayed R, Taglialatela G (2008) Selective induction of calcineurin activity and signaling by oligomeric amyloid beta. Aging Cell 7:824-835.

Schwartz N, Schohl A, Ruthazer ES (2009) Neural activity regulates synaptic properties and dendritic structure in vivo through calcineurin/NFAT signaling. Neuron 62:655-669.

Shankar GM, Bloodgood BL, Townsend M, Walsh DM, Selkoe DJ, Sabatini BL (2007) Natural oligomers of the Alzheimer amyloid- $\beta$ protein induce reversible synapse loss by modulating an NMDA-type glutamate receptor-dependent signaling pathway. J Neurosci 27:2866-2875.

Shankar GM, Li S, Mehta TH, Garcia-Munoz A, Shepardson NE, Smith I, Brett FM, Farrell MA, Rowan MJ, Lemere CA, Regan CM, Walsh DM, Sabatini BL, Selkoe DJ (2008) Amyloid-beta protein dimers isolated directly from Alzheimer's brains impair synaptic plasticity and memory. Nat Med 14:837-842.

Smith IF, Green KN, LaFerla FM (2005) Calcium dysregulation in Alzheimer's disease: recent advances gained from genetically modified animals. Cell Calcium 38:427-437.

Snyder EM, Nong Y, Almeida CG, Paul S, Moran T, Choi EY, Nairn AC, Salter MW, Lombroso PJ, Gouras GK, Greengard P (2005) Regulation of NMDA receptor trafficking by amyloid-beta. Nat Neurosci 8:1051-1058. Spires-Jones TL, de Calignon A, Matsui T, Zehr C, Pitstick R, Wu HY, Osetek JD, Jones PB, Bacskai BJ, Feany MB, Carlson GA, Ashe KH, Lewis J, Hyman BT (2008) In vivo imaging reveals dissociation between caspase activation and acute neuronal death in tangle-bearing neurons. J Neurosci 28:862-867.

Spires TL, Meyer-Luehmann M, Stern EA, McLean PJ, Skoch J, Nguyen PT, Bacskai BJ, Hyman BT (2005) Dendritic spine abnormalities in amyloid precursor protein transgenic mice demonstrated by gene transfer and intravital multiphoton microscopy. J Neurosci 25:7278-7287.

Springer JE, Azbill RD, Nottingham SA, Kennedy SE (2000) Calcineurinmediated BAD dephosphorylation activates the caspase-3 apoptotic cascade in traumatic spinal cord injury. J Neurosci 20:7246-7251.

Stutzmann GE (2005) Calcium dysregulation, IP3 signaling, and Alzheimer's disease. Neuroscientist 11:110-115.

Sze CI, Troncoso JC, Kawas C, Mouton P, Price DL, Martin LJ (1997) Loss of the presynaptic vesicle protein synaptophysin in hippocampus correlates with cognitive decline in Alzheimer disease. J Neuropathol Exp Neurol 56:933-944.

Taglialatela G, Hogan D, Zhang WR, Dineley KT (2009) Intermediate- and long-term recognition memory deficits in $\mathrm{Tg} 2576$ mice are reversed with acute calcineurin inhibition. Behav Brain Res 200:95-99.

Terry RD, Masliah E, Salmon DP, Butters N, DeTeresa R, Hill R, Hansen LA, Katzman R (1991) Physical basis of cognitive alterations in Alzheimer's disease: synapse loss is the major correlate of cognitive impairment. Ann Neurol 30:572-580.

Townsend M, Shankar GM, Mehta T, Walsh DM, Selkoe DJ (2006) Effects of secreted oligomers of amyloid beta-protein on hippocampal synaptic plasticity: a potent role for trimers. J Physiol 572:477-492.

Uchino H, Kuroda Y, Morota S, Hirabayashi G, Ishii N, Shibasaki F, Ikeda Y, Hansson MJ, Elmér E (2008) Probing the molecular mechanisms of neuronal degeneration: importance of mitochondrial dysfunction and calcineurin activation. J Anesth 22:253-262.

Walsh DM, Selkoe DJ (2004) Deciphering the molecular basis of memory failure in Alzheimer's disease. Neuron 44:181-193.

Wang JH, Kelly PT (1996) The balance between postsynaptic $\mathrm{Ca}^{2+}$ dependent protein kinase and phosphatase activities controlling synaptic strength. Learn Mem 3:170-181.

Winder DG, Sweatt JD (2001) Roles of serine/threonine phosphatases in hippocampal synaptic plasticity. Nat Rev Neurosci 2:461-474.

Wu HY, Tomizawa K, Oda Y, Wei FY, Lu YF, Matsushita M, Li ST, Moriwaki A, Matsui H (2004) Critical role of calpain-mediated cleavage of calcineurin in excitotoxic neurodegeneration. J Biol Chem 279:4929-4940.

Yaari R, Corey-Bloom J (2007) Alzheimer's disease. Semin Neurol 27: 32-41.

Zeng H, Chattarji S, Barbarosie M, Rondi-Reig L, Philpot BD, Miyakawa T, Bear MF, Tonegawa S (2001) Forebrain-specific calcineurin knockout selectively impairs bidirectional synaptic plasticity and working/episodiclike memory. Cell 107:617-629. 